\title{
Breeding for reduced methane emission and feed-efficient Holstein cows: An international response
}

\author{
C. I. V. Manzanilla-Pech, ${ }^{1 *} \odot$ P. Løvendahl, ${ }^{1} \odot$ D. Mansan Gordo, ${ }^{1} \odot$ G. F. Difford, ${ }^{1} \odot$ J. E. Pryce ${ }^{2,3} \odot$ \\ F. Schenkel, ${ }^{4} \odot$ S. Wegmann, ${ }^{5} \odot$ F. Miglior, ${ }^{4} \odot$ T. C. Chud, ${ }^{4} \odot$ P. J. Moate, ${ }^{6,7} \odot$ S. R. O. Williams, ${ }^{7} \odot$ \\ C. M. Richardson, ${ }^{2,3} \odot$ P. Stothard, ${ }^{8} \odot$ and J. Lassen ${ }^{9}$ \\ ${ }^{1}$ Center for Quantitative Genetics and Genomics, Aarhus University, PO Box 50, DK-8830 Tjele, Denmark \\ ${ }^{2}$ Agriculture Victoria, AgriBio, Centre for AgriBioscience, Bundoora, Victoria 3083, Australia \\ ${ }^{3}$ School of Applied Systems Biology, La Trobe University, Bundoora, Victoria 3083, Australia \\ ${ }^{4}$ Centre for Genomic Improvement of Livestock, Department of Animal Biosciences, University of Guelph, Guelph, ON, N1G 2W1, Canada \\ ${ }^{5}$ Qualitas AG, 6300 Zug, Switzerland \\ ${ }^{6}$ Centre for Agricultural Innovation, School of Agriculture and Food, Faculty of Veterinary and Agricultural Sciences, The University of Melbourne, \\ Victoria 3083, Australia \\ ${ }^{7}$ Agriculture Victoria Research, Ellinbank, Victoria 3820, Australia \\ ${ }^{8}$ Faculty of Agricultural, Life and Environmental Science, Agriculture, Food and Nutrition Sciences Department, University of Alberta, Edmonton, \\ AB, T6G 2C8, Canada \\ ${ }^{9}$ Viking Genetics, Ebeltoftvej 16, Assenstoft, 8960 Randers, Denmark
}

\section{ABSTRACT}

Selecting for lower methane $\left(\mathrm{CH}_{4}\right)$ emitting animals is one of the best approaches to reduce $\mathrm{CH}_{4}$ given that genetic progress is permanent and cumulative over generations. As genetic selection requires a large number of animals with records and few countries actively record $\mathrm{CH}_{4}$, combining data from different countries could help to expedite accurate genetic parameters for $\mathrm{CH}_{4}$ traits and build a future genomic reference population. Additionally, if we want to include $\mathrm{CH}_{4}$ in the breeding goal, it is important to know the genetic correlations of $\mathrm{CH}_{4}$ traits with other economically important traits. Therefore, the aim of this study was first to estimate genetic parameters of 7 suggested methane traits, as well as genetic correlations between methane traits and production, maintenance, and efficiency traits using a multicountry database. The second aim was to estimate genetic correlations within parities and stages of lactation for $\mathrm{CH}_{4}$. The third aim was to evaluate the expected response of economically important traits by including $\mathrm{CH}_{4}$ traits in the breeding goal. A total of 15,320 methane production (MeP, g/d) records from 2,990 cows belonging to 4 countries (Canada, Australia, Switzerland, and Denmark) were analyzed. Records on dry matter intake (DMI), body weight (BW), body condition score, and milk yield (MY) were also available. Additional traits such as methane yield (MeY; $\mathrm{g} / \mathrm{kg} \mathrm{DMI}$ ), methane intensity (MeI; g/kg energy-cor-

Received November 10, 2020.

Accepted April 14, 2021.

*Corresponding author: coralia.manzanilla@qgg.au.dk rected milk), a genetic standardized methane production, and 3 definitions of residual methane production $(\mathrm{g} / \mathrm{d})$, residual feed intake, metabolic BW (MBW), BW change, and energy-corrected milk were calculated. The estimated heritability of $\mathrm{MeP}$ was 0.21 , whereas heritability estimates for $\mathrm{MeY}$ and $\mathrm{MeI}$ were 0.30 and 0.38 , and for the residual methane traits heritability ranged from 0.13 to 0.16 . Genetic correlations between different methane traits were moderate to high (0.41 to 0.97$)$. Genetic correlations between $\mathrm{MeP}$ and economically important traits ranged from 0.29 (MY) to 0.65 (BW and MBW), being 0.41 for DMI. Selection index calculations showed that residual methane had the most potential for inclusion in the breeding goal when compared with $\mathrm{MeP}, \mathrm{MeY}$, and $\mathrm{MeI}$, as residual methane allows for selection of low methane emitting animals without compromising other economically important traits. Inclusion of residual feed intake in the breeding goal could further reduce methane, as the correlation with residual methane is moderate and elicits a favorable correlated response. Adding a negative economic value for methane could facilitate a substantial reduction in methane emissions while maintaining an increase in milk production.

Key words: methane production, residual methane, methane yield, feed efficiency

\section{INTRODUCTION}

Increases in dairy production are needed to fulfill the demand of the growing world population for animal protein. According to the FAO, the world milk output reached 827 million tons in 2018, which represents a $2 \%$ increase in production compared with 2017 (FAO, 
IFAD, UNICEF, WFP, and WHO, 2018). This constant increase presents long-term challenges of economic feasibility as well as environmental sustainability. Methane gas $\left(\mathrm{CH}_{4}\right)$, generated consequentially through enteric fermentation in ruminants, may compromise the sustainability of dairy products. Methane gas in livestock represents $17 \%$ of the global greenhouse emissions (Knapp et al., 2014) and 2 to $12 \%$ of feed energy losses in ruminants (Johnson et al., 1994). Thus, reducing $\mathrm{CH}_{4}$ emissions in livestock production is one of the challenges of this century and researchers from different disciplines including nutrition, physiology, and genetics have made substantial efforts to contribute research to develop tools that can help reduce $\mathrm{CH}_{4}$ emissions (Johnson and Johnson, 1995; Boadi et al., 2004; Amon et al., 2006; Knapp et al., 2014).

In the last decade, several studies (Lassen and Løvendahl, 2016; Pszczola et al., 2017; van Engelen, 2018; Breider et al., 2018; Difford et al., 2018) have shown that $\mathrm{CH}_{4}$ traits in dairy cattle have low to moderate heritability, from 0.11 to 0.33 . Consequently, selecting for animals with low $\mathrm{CH}_{4}$ emissions is a strong approach to reduce $\mathrm{CH}_{4}$, given that genetic progress is permanent and cumulative over generations. Genetic selection, however, requires a large number of animals with records to predict accurate breeding values. Currently, the data available on $\mathrm{CH}_{4}$ emissions are scarce or nonexistent in most countries, as measuring $\mathrm{CH}_{4}$ is expensive and labor intensive, and targeting $\mathrm{CH}_{4}$ reductions has only gained impetus in the last decade. Combining data from different countries is an attractive solution to increase data set size and subsequently improve accuracy of genetic parameters for MeP, compared with only using data from one country. Additionally, genetic correlations with economically important traits can be estimated more accurately, making it possible to include $\mathrm{CH}_{4}$ traits in future breeding goals.

Despite the importance of $\mathrm{CH}_{4}$ emissions, there is a lack of consensus on the most appropriate trait to be included in the breeding goal (de Haas et al., 2017). Should it be daily $\mathrm{CH}_{4}$ production in $\mathrm{g} / \mathrm{d}(\mathbf{M e P})$ per cow, regardless of the correlation with traits such as MY, BW, and DMI, which are already included in the breeding objective? Alternatively, should it be a ratio trait such as $\mathrm{CH}_{4}$ yield $\left[\mathrm{MeY} ; \mathrm{CH}_{4}(\mathrm{~g} / \mathrm{d}) / \mathrm{DMI}(\mathrm{kg} / \mathrm{d})\right]$, or $\mathrm{CH}_{4}$ intensity [MeI; $\left.\mathrm{CH}_{4}(\mathrm{~g} / \mathrm{d}) / \mathrm{ECM}(\mathrm{kg} / \mathrm{d})\right]$ or a residual $\mathrm{CH}_{4}$ trait, adjusted by metabolic body weight (MBW), ECM, or DMI? An important but rather subtle distinction must be made between breeding objective traits and selection index traits, as they are not always the same. For example, the breeding objective could be to improve MeI, but to achieve this, MeP and ECM are included in the selection index and not MeI directly. Informing the relative merit of different breeding objectives and different traits included in the selection indices requires knowledge of their genetic parameters. Therefore, genetic correlations between $\mathrm{CH}_{4}$ traits and efficiency traits are needed to help elucidate the genetic background behind the energy losses and to help identify the most appropriate $\mathrm{CH}_{4}$ trait to be included in the breeding objective.

Last, at present there remains a lack of consensus on which is the most practical and cost-effective method to measure $\mathrm{CH}_{4}$ emissions. Respiration chambers are considered the gold standard; however, the high capital investment cost and the limitation of having only one animal per chamber at the same time makes genetic evaluations extremely challenging. More recently, other methods have gained popularity, for example, sniffers (Garnsworthy et al., 2012a; Lassen et al., 2012), $\mathrm{SF}_{6}$ tracer gas (Grainger et al., 2007; Deighton et al., 2014), and an automated head chamber system (GreenFeed, C-lock Inc.), which allow measurements on larger numbers of animals per day in different conditions such as grazing or indoor barns. Fortunately, $\mathrm{CH}_{4}$ emissions as measured by sniffers, the $\mathrm{SF}_{6}$ tracer technique, and automated head chamber system have been reported to be highly correlated with measurements made by the respiration chamber technique $(\sim 0.80$, Garnsworthy et al., 2012b; Deighton et al., 2014; Difford et al., 2019).

In this study, a substantial international effort in 4 different countries made it possible to establish a very large international database, with more than 15,000 $\mathrm{MeP}$ records from around 3,000 cows. The main aim of this study were to estimate genetic parameters of 7 potential $\mathrm{CH}_{4}$ traits, and the second aim was to determine genetic correlations between $\mathrm{CH}_{4}$ traits and production, maintenance and efficiency traits using a multicountry database. A third aim was to determine how these correlations change with different stages of lactation and parities. A fourth aim was to evaluate the expected response of economically important traits by including $\mathrm{CH}_{4}$ traits in the breeding goal.

\section{MATERIALS AND METHODS}

The Efficient Dairy Genome Project (EDGP, www .genomedairy.ualberta.ca) is an international initiative that combines data from 6 countries (Australia, Canada, Denmark, United Kingdom, United States, and Switzerland) aiming to build one genomic reference population and a unique database of DMI records. Additionally, other traits were recorded on some of those animals, including milk contents recorded routinely and maintenance traits such as BW and BCS. Methane was measured in 4 of the 6 countries participating in the initiative: Australia, Canada, Switzerland, and Denmark. Feed intake data comes from historical experiments 
that covered 20 yr, between 1998 and 2018, whereas MeP data are only from the last 6 yr (2013-2018).

\section{Data Collection: Production and Maintenance Traits}

Denmark. A total of 64,919 weekly records on DMI, BW, BCS, and milk yield (MY) were available from 2,722 cows from 2 research farms and 10 commercial farms collected between 1992 and 2016 . Cows were located at Ammitsbøl Skovgaard research herd (Skovgaard, Vejle, Denmark) until 2000 and were subsequently relocated to the Danish Cattle Research Center (DCRC, Foulum, Denmark) in 2001 to 2016 as reported in Li et al. (2017). Cows were fed manually at Ammitsbøl Skovgaard (tiestall barn) 3 to 5 times per day, individual refusals were recorded daily, and samples were collected weekly to estimate DM content. At DCRC, automated feeders (Insentec, RIC system) were used. Cows were part of numerous nutritional experiments and diets included primarily rolled barley, corn silage, grass clover silage, rapeseed meal, and soybean meal. Body weight was measured either once per week or automatically at each milking, and averaged per week (full description can be found in Li et al., 2017). Body condition was scored to the nearest half unit from 1 to 5 . To minimize the influence from milking and feeding, the cows were on the Danish scale (Kristensen, 1986) derived from Lowman et al. (1976), where 1 is an extremely thin animal, 3 is an animal in optimal body condition, and 5 is obese. For this analysis, the score was multiplied by 100. The research barn at Ammitsbøl Skovgaard was a tiestall system, with twice daily milking and sampling to measure milk quantity and components (fat, protein, and lactose content). Weekly averages for DMI and MY were calculated per cow. The DCRC barn is a loose housing system with access to automatic milking stations (AMS; DeLaval International $\mathrm{AB})$. The AMS was fitted with a weighing platform (Danvaegt) that recorded BW at each milking. For the 10 commercial farms, weekly MY and milk components were available by the national recording scheme (RYK, Skejby, Denmark).

Australia. A total of 22,005 weekly records on DMI, 15,277 on BW, and 22,438 on MY (576 multiparous cows), and 17,687 on BCS (496 cows) from the National Centre for Dairy Research and Development (Ellinbank, VIC, Australia) were available. Individual cow feed intakes were measured for the 5 - $\mathrm{C} \mathrm{CH}_{4}$ measurement period using an electronic feed recording system (Gallagher Animal Management Systems). The cows were fed compressed dairy cubes ad libitum and the cubes were comprised of approximately $74 \%$ alfalfa hay (Medicago sativa L.), $25 \%$ crushed barley (Hordeum vulgare L.) grain, and 1\% mineral mix (Multicube Ltd.).
Weekly averages for DMI and milk composition were calculated per cow. Body condition score was measured on an 8-point scale according to their national scoring system, where a cow with a BCS of 1 is considered extremely thin, the result either of severe underfeeding or disease, and a cow with a BCS of 8 is considered extremely fat and is at risk of several metabolic diseases after calving (Dairy Australia, 2018). Posteriorly, this scale was converted to the 5-point scale and multiplied by 100 to merge with the data sets from the other countries. Daily milk records were available throughout the recording period, with fat and protein percentages obtained through mid-infrared spectroscopy (Richardson et al., 2021).

Canada. In total 123,858 daily records on DMI, and 62,415 weekly records on MY and milk composition data (783 cows), 21,826 weekly records on BCS (385 cows) and 6,532 records (daily, weekly) on BW (311 cows) from 2 research stations: Ontario Dairy Research Centre (ODRC-Elora, ON, Canada) and Dairy Research and Technology Center (DRTC-Edmonton, $\mathrm{AB}$, Canada). At ODRC, feed intake was measured from $30 \mathrm{~d}$ before calving to 150 DIM in first-lactation cows housed in a freestall system (Seymour et al., 2019). Feed intake was daily recorded by automated feeders (Insentec, RIC system). In the tiestall barn feed was weighted manually before delivery (once per day) and any remaining feed was manually weighed $24 \mathrm{~h}$ later, before the next feed delivery. Details about the ingredients and chemical composition of all rations offered to the cows were described by Seymour et al. (2019). Weekly samples of rations were taken and analyzed for DM content (Seymour et al., 2019). From 2016 to November 2017 BW were measured every 2 wk using a conventional scale. From March 2017, BW and BCS were daily recorded automatically using an in-line scale and score-cameras (DeLaval), respectively, located in the rotary parlor and voluntary milking system (VMS) after each milking. Cows were milked twice daily in a rotary parlor (DeLaval) or in place (tiestall barn) or using a VMS (DeLaval). Automatic milk weights were either recorded in the rotary milking parlor and VMS or manually in the tiestall system and milk samples were collected weekly at alternating morning or evening milking for composition analysis. At the DRTC, feed intake was measured from 3 to 240 DIM in multiparous cows housed in a tiestall system, where each cow had an individual feeding bin. Feed intake was manually daily recorded by weighing feed before feeding and weighing leftover feed after a 24-h period. Weekly samples of the TMR were assessed and analyzed for DM content. Once each month, cows were weighed after a morning milking and before feeding. The BCS was recorded during weighing according to 
the Canadian Body Condition Scoring of Dairy Cattle from 1 to 5 (Rodenburg, 2004), and these data were multiplied by 100 for consistency with the other data sets. Milk weights were recorded twice a day during each milking session and milk sampling was conducted once per week. Weekly averages for DMI and BW were calculated per cow for both ODRC and DRTC herds.

Switzerland. A total of 6,354 daily records on DMI, 6,078 on BW (99 cows), 8,478 on MY, and 104 records on BCS (99 cows) from Agroscope Posieux research station were accessible. Weekly averages for DMI, BW, and MY were calculated per cow. Body condition was scored from 100 to 500. At Agroscope Posieux, cows grazed on pasture from April to the end of October. The pasture sward consisted mainly of grasses $(76 \%$ $\pm 10)$, and some legumes $(16 \% \pm 8)$ and herbs $(8 \%$ \pm 14 ). Cows received 2 to $4 \mathrm{~kg}$ of energy concentrate, depending on their individual MY. Herbage intake of 20 cows was estimated individually twice for $7 \mathrm{~d}$ during summer using the alkane double-indicator technique (Mayes et al., 1986). From November to March, cows were kept in a freestall barn where they were fed mixed rations, consisting of corn silage, grass silage, alfalfa (dehydrated or silage), hay (approximately 32-40\%, $27 \%, 14 \%, 13-18 \%, 6 \%$ ), and no or limited amounts of concentrate. While the cows were kept in a freestall barn, the feed intake was recorded by means of automated feeders (Insentec, RIC system).

\section{Data Collection: Methane}

Denmark. A total of 14,013 weekly records on $\mathrm{CH}_{4}$ concentration $(\mathrm{ppm})$ from 2,725 cows were available from DCRC $(1,328)$ and 10 commercial farms $(1,397)$ in Denmark collected between 2011 and 2016, described previously in Zetouni et al. (2018) and Difford et al. (2016, 2020). Methane concentration was measured by 2 sniffer methods: the nondispersive infrared $\mathrm{CH}_{4}$ sensor (Guardian NG, Edinburgh Instruments Ltd.) in the research farms and the portable Fourier transform infrared Gasmet DX-4000 (Gasmet, Gasmet Technologies $\mathrm{Oy}$ ) in the commercial farms. The Fourier transform infrared and nondispersive infrared devices were installed in the AMS feed bins and $\mathrm{CH}_{4}$ and carbon dioxide $\left(\mathrm{CO}_{2}\right.$; used to calculate $\left.\mathrm{CH}_{4} \mathrm{~g} / \mathrm{d}\right)$ gas concentrations (ppm) were sampled continuously (Lassen et al., 2012). The AMS visit data and breath gas concentration (time series) on a 1-s basis were merged using a time-alignment algorithm (Difford et al., 2016). Mean $\mathrm{CH}_{4}$ and $\mathrm{CO}_{2}$ gas concentrations were corrected for environmental factors, including diurnal variation and differences across days using a linear mixed model following Difford et al. (2016) to calculate daily averages.
Furthermore, $\mathrm{CH}_{4}$ data (from research and commercial herds) were filtered to only include weekly averages where a maximum of $3 \mathrm{~d}$ were missing within each week of measurement and each cow had a minimum of 3 weekly measurements. The concordance correlation coefficient between respiration chamber $\mathrm{CH}_{4}$ emissions and sniffers (Guardian) $\mathrm{CH}_{4}$ concentration is 0.77 (Difford et al., 2020). Both methodologies were described and compared previously (Difford et al., 2016). To have a unique phenotype comparable with the other countries, $\mathrm{MeP}$ in g/d was calculated. First, computing $\mathrm{CH}_{4}$ in liters using the following formula of Madsen et al. (2010) based on heat-producing units (HPU):

$$
\begin{aligned}
\mathrm{CH}_{4}(\mathrm{~L} / \mathrm{d})= & \mathrm{CH}_{4} / \mathrm{CO}_{2} \times 180 \times 24 \times \mathrm{HPU}, \text { where } \\
\mathrm{HPU} & =5.6 \mathrm{MBW}+22 \mathrm{ECM}+1.6 \\
& \times 10^{-5} \text { days carried calf. }
\end{aligned}
$$

Second, converting $\mathrm{CH}_{4}$ in $\mathrm{L} / \mathrm{d}$ to $\mathrm{g} / \mathrm{d}$ using the formula:

$$
\operatorname{MeP}(\mathrm{g} / \mathrm{d})=\text { density } \times \mathrm{L} / \mathrm{d},
$$

where the density of $\mathrm{CH}_{4}$ at $20^{\circ} \mathrm{C}=0.668 \mathrm{~g} / \mathrm{L}$.

After calculating MeP, only 10,569 records remained from 2,224 cows; most of the lost records were due to the lack of simultaneous information on MBW and ECM, required to calculate this trait.

Australia. In total 2,105 daily records on $\mathrm{MeP}$ were available from 463 Australian lactating cows. These cows were part of a $\mathrm{CH}_{4}$ experiment carried out at the Department of Economics Development, Jobs, Precincts and Regions, Ellinbank (National Centre for Dairy Research and Development). The $\mathrm{CH}_{4}$ measurements took place in 3 batches each spring from 2013 to 2017, where $\mathrm{MeP}$ was measured over a period of 3 to $5 \mathrm{~d}$ with the use of the sulfur hexafluoride $\left(\mathrm{SF}_{6}\right)$ tracer technique (Deighton et al., 2014). Animals were between 68 and 187 DIM at the start of the measurement, and across parities (1 to 9$)$. A detailed description of the data recording has been described previously Richardson et al. (2021). The $\mathrm{SF}_{6}$ tracer technique (Deighton et al., 2014) measures the enteric MeP using $\mathrm{SF}_{6}$ as a tracer gas, allowing $\mathrm{CH}_{4}$ emissions to be measured from confined, free range, and grazing animals. The concordance correlation coefficient between respiration chamber $\mathrm{CH}_{4}$ and the $\mathrm{SF}_{6} \mathrm{CH}_{4}$ is reported to be high at 0.83 (Deighton et al., 2014).

Canada. In total, 2,141 daily records on $\mathrm{MeP}$ from 279 cows from 2 research stations ODRC and DRTC 
Table 1. Number of records (cows) of original traits per country after editing

\begin{tabular}{lccrr}
\hline & \multicolumn{4}{c}{ Number of records (cows) } \\
& \multicolumn{1}{c}{ Denter editing } \\
\cline { 2 - 4 } Trait $^{1}$ & \multicolumn{2}{c}{ Australia } & Canada & \multicolumn{1}{c}{ Switzerland } \\
\hline MeP & $9,455(2,224)$ & $2,105(461)$ & $1,698(246)$ & $547(59)$ \\
DMI & $61,646(882)$ & $19,743(576)$ & $70,700(763)$ & $5,778(99)$ \\
BW & $19,566(2,698)$ & $19,710(576)$ & $60,267(309)$ & $6,122(99)$ \\
BCS & $15,227(846)$ & $23,095(495)$ & $24,355(376)$ & $100(99)$ \\
MY & $63,821(2,714)$ & $19,437(576)$ & $73,687(773)$ & $7,715(99)$ \\
\hline
\end{tabular}

${ }^{1} \mathrm{MeP}=$ methane production; $\mathrm{MY}=$ milk yield .

were available. The $\mathrm{MeP}$ was measured over a period of 4 to $7 \mathrm{~d}$. The method to measure $\mathrm{CH}_{4}$ in both herds was GreenFeed (C-Lock Inc.). GreenFeed is an automated head chamber system that monitors $\mathrm{CH}_{4}$ and $\mathrm{CO}_{2}$ mass fluxes from the breath and eructation gas of ruminants (Zimmerman et al., 2011). The concordance correlation between respiration chamber $\mathrm{CH}_{4}$ and GreenFeed $\mathrm{CH}_{4}$ was reported to be high with 0.84 in beef cattle (Velazco et al., 2016). At ODRC, groups from 2 to 4 cows at approximately 120 to 150 DIM were moved from the freestall barn to a separate tiestall wing $3 \mathrm{~d}$ before the $\mathrm{CH}_{4}$ testing. Animals were fed TMR ad libitum which was delivered daily at approximately $1100 \mathrm{~h}$. Methane emissions were measured for 10 to 12 min 4 times daily over the following $5 \mathrm{~d}$ at $0800,1200,1600$, and $2000 \mathrm{~h}$. At DRTC herd, cows ranging from 30 to 250 DIM and fed TMR ad libitum, which was delivered daily at approximately $0800 \mathrm{~h}$. Methane emission measurements were collected in batches (10-15 cows/batch), where each batch was measured for $12 \mathrm{~d}$ (twice a day, $12 \mathrm{~h}$ apart). The first-day measurement started at 0100 and $1300 \mathrm{~h}$, subsequently shifted every day by $1 \mathrm{~h}$ to cover the 24 -h cycle by $12 \mathrm{~d}$ of recording. Similar to ODRC each cow was measured by $10 \mathrm{~min}$ of each visit to the GreenFeed device. Methane records of each cow from both herds were daily averages.

Switzerland. In total, 547 weekly records on $\mathrm{MeP}$ from 59 cows from the research station Agroscope Posieux were available. At the Agroscope Posieux research station, the $\mathrm{CH}_{4}$ emission was measured by 2 GreenFeed devices (C-Lock Technology Inc.). In the present experiments, cows were allowed a maximum of 6 visits to the station per day, one per 3-h time slot, and encouraged to stay by releasing up to 8 portions of $32 \mathrm{~g}$ of pelleted dried whole corn plant per visit. The procedure of calculating daily $\mathrm{CH}_{4}$ production from the data obtained per visit and per day is described in detail by Huhtanen et al. (2015). The $\mathrm{CH}_{4}$ production data derived from the GreenFeed system were first averaged for each hour of the day, to account for variations in the distribution of visits over the day. Subsequently, data were averaged over $7 \mathrm{~d}$. In the grazing season, one
GreenFeed unit was set up on the paddock next to the water trough. Another GreenFeed device was arranged in a cubicle in the freestall barn, thus cows had access to a GreenFeed device any time except during milking. In winter, a GreenFeed unit was placed in the barn. For each weekly $\mathrm{CH}_{4}$ value, one corresponding daily milk sample was available; additionally, for 20 cows, a sample was taken at each milking during 2 wk.

\section{Editing and Calculation of Derived Traits}

For all traits, parities from fourth parity onward were included in the third parity class, to avoid losing animals due to the small number of animals present in later parities. In addition, $\mathrm{CH}_{4}$ per parity was also a trait, and this merging was done to be able to estimate the genetic parameters. We kept only records from DIM 5 to 350 and from cows with age at calving between 20 and 150 mo. Records deviating more than $3 \mathrm{SD}$ from the mean for each trait were set as missing. Number of records and cows per trait (original traits) before and after editing per country are presented in Table 1.

The calculation of derived traits (traits that include one or more of the original traits: MeP, DMI, BW, $\mathrm{MY}$, and BCS) was done on the combined database of the 4 countries. Metabolic BW was defined as $\mathrm{BW}^{0.75}$. Change in BW $(\boldsymbol{\Delta B W})$ was calculated as (actual BW - BW nadir)/(actual DIM - DIM nadir). Energy-corrected milk was calculated using the following formula (Sjaunja et al., 1991):

$$
\begin{aligned}
\operatorname{ECM}(\mathrm{kg})= & 0.25 \text { milk }(\mathrm{kg})+12.2 \text { fat content }(\mathrm{kg}) \\
& +7.7 \text { protein content }(\mathrm{kg}) .
\end{aligned}
$$

Residual feed intake 1 (RFI1) was the residual of the partial regression of DMI on MBW, ECM, and $\triangle \mathrm{BW}$ (according to the 2-steps RFI from Tempelman et al., 2015), along with fixed effects described in model [5]. An additional residual feed intake (RFI2) was based on the partial regression on MBW and ECM only, excluding $\Delta \mathrm{BW}$. Likewise, residual $\mathrm{CH}_{4} 1$ (RMet1) was the residual of the partial regression of $\mathrm{MeP}$ on $\mathrm{MBW}$ and 
DMI, RMet2 was the residual of the partial regression on MBW and ECM, and RMet3 was the residual of the partial regression on MBW, DMI, and ECM along with fixed effects described in model [5]. Methane yield (MeY) was defined as MeP divided by DMI, whereas MeI was calculated using MeP divided by ECM. These $5 \mathrm{CH}_{4}$ traits will be referred to as adjusted $\mathrm{CH}_{4}$ traits in future references for practical reasons.

\section{Variance Component Estimation}

For each trait (MeP, MeY, MeI, RMet1, RMet2, RMet3, DMI, RFI1, RFI2, BW, MBW, $\triangle \mathrm{BW}, \mathrm{BCS}$, $\mathrm{MY}$, and ECM), variance components were estimated using the AI-REML algorithm with the DMU software (Version 6, Release 5.4; Madsen and Jensen, 2014). Genetic and phenotypic correlations were estimated through pairwise bivariate analyses between the traits. A pedigree containing the identification of the cow, sire, and dam with 29,337 animals (after pruning) in the relationship matrix was used.

The model used to estimate the variance components for $\mathrm{CH}_{4}$ traits was

$$
\begin{aligned}
y_{i j k l m n o}=\mu+ & H T Y S_{i}+\text { Meth }_{j}+D I M_{k}+A C C_{l}(P N) \\
& +a_{m}+p e_{n}+e_{i j k l m n o},
\end{aligned}
$$

where $y_{i j k l m n o}$ is the phenotype for MeP, MeY, and MeI; $\mu$ is the mean; HTYS is the fixed effect $i$ for herd-trialyear-season (65-89 classes); Meth is the fixed effect $j$ for measurement method of $\mathrm{CH}_{4}$ (4 classes); DIM is the fixed effect $k$ for DIM modeled with the Wilmink function (Wilmink, 1987); $P N$ is the fixed effect for the $l$ parity number ( 3 classes); and $A C C$ is the age of cow at calving in months as covariate. Random effects are as follows: $a$ is the additive genetic effect $m$ distributed as $N\left(\mathbf{0}, \mathbf{A} \sigma_{a}^{2}\right)$, in which $\mathbf{A}$ is the relationship matrix and $\sigma_{a}^{2}$ is the genetic variance, pe the permanent environmental effect $n$ (within and across parities) distributed as $N\left(\mathbf{0}, \mathbf{I} \sigma_{p e}^{2}\right)$, in which $\mathbf{I}$ is an identity matrix and $\sigma_{p e}^{2}$ is the permanent environmental variance, and $e$ is the residual effect $o$ of $y_{i j k l m n}$. The model for DMI, BW, MBW, $\triangle \mathrm{BW}$, and BCS was the same as [5] but excluding the Meth fixed effect. Likewise, the model for the milk traits (MY and ECM) included the effect of frequency of milking (2 classes: robot or 2 milkings AM: PM) instead of Meth. Given that fixed effects were accounted for already when calculating the residual traits (RFI1, RFI2, RMet1, RMet2, and RMet3), their model only included the mean, additive genetic effect, permanent environmental effect, and residual effect.

\section{MeP per Country, Method, Parity, and Stage of Lactation}

With the aim of partitioning the variation and estimating the heritability of MeP, within country analyses were conducted despite the small amount of data from some countries. Likewise, analyses between methods of measurement ( $\mathrm{SF}_{6}$, GreenFeed, Guardian, and Gasmet) were conducted to estimate the genetic parameters per method. Bivariate analyses were performed between countries and methods with inconclusive results (convergence problems) probably due to the lack of information and the poor genetic links between the groups. Additionally, to determine whether MeP heritability varies across parities and lactation stages, $\mathrm{MeP}$ records were divided by parity $(1,2$, and $3+$ ) and stage of lactation: early (from 5 to 100 DIM), mid- (from 101 to 200 DIM), and late lactation (from 201 DIM onward). Genetic parameters, including genetic correlations, were estimated using model [5] in univariate and bivariate analyses. Permanent environmental co-variances and residual co-variances between the different lactation stages and parities were set to zero; consequently, it was not possible to estimate the phenotypic correlations between stages and parities. Given the small number of animals with $\mathrm{CH}_{4}$ records per country and weak links between their pedigrees, it was not possible to estimate genetic correlations of $\mathrm{MeP}$ between countries.

\section{Genetic Standardized Methane}

With the results of the genetic parameters per country, a genetic standardized $\mathrm{CH}_{4}$ (GSMet, g/d) trait was calculate based on the following formula:

$$
\begin{gathered}
\text { GSMet }(\mathrm{g} / \mathrm{d})=\mathrm{MeP} /(\text { country genetic SD/ } \\
\text { mean genetic SD across countries })
\end{gathered}
$$

With the objective to test the difference between a standardized $\mathrm{CH}_{4}$ trait and $\mathrm{MeP}$, correlations between GSMet and all the other traits (including MeP) were estimated and presented in this study.

\section{Correlated Response of Selection}

Some interesting questions arise when considering selecting for lower $\mathrm{CH}_{4}$-emitting animals. One is the effect of selection on economically important traits, including milk production, feed intake, and BW. To investigate this, we developed 4 selection indexes that included 4 traits each: (index 1) MeP, DMI, MBW, and ECM; (index 2) RMet, DMI, MBW, and ECM; (index 3) MeP, RFI, MBW, and ECM; and (index 4) RMet, 
Manzanilla-Pech et al.: GENETICS OF METHANE AND FEED EFFICIENCY

Table 2. Descriptive statistics for methane, production, maintenance, and efficiency traits for a combined data set

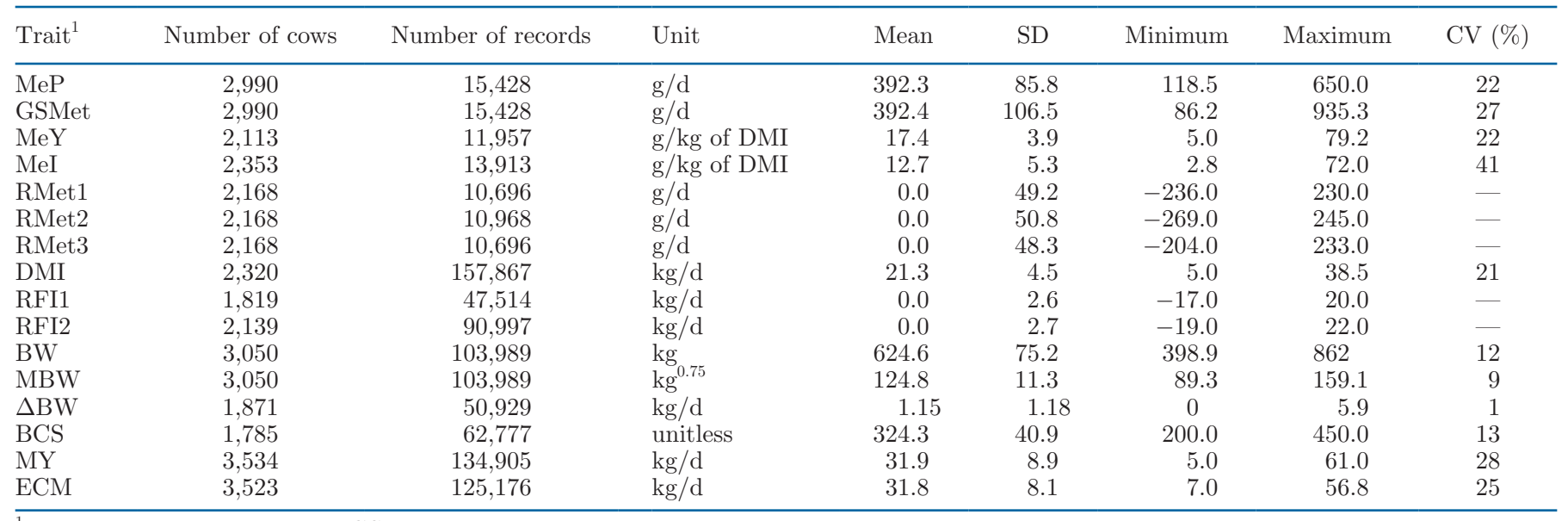

${ }^{1} \mathrm{MeP}=$ methane production; GSMet $=$ genetic standardized methane; $\mathrm{MeY}=$ methane vield: MeI = methane intensity; $\mathrm{RMet1}=$ residual methane on metabolic body weight (MBW) and DMI; RMet2 = residual methane on MBW and ECM; RMet3 = residual methane on MBW, DMI, and ECM; RFI1 = residual feed intake (residual of DMI on MBW, ECM, and $\triangle \mathrm{BW}$ ); RFI2 = residual feed intake (residual of DMI on MBW and ECM); $\triangle \mathrm{BW}=$ change in BW; BCS was recorded on a 1 to 5 scale and then multiplied by $100 ; \mathrm{MY}=$ milk yield.

RFI, MBW, and ECM. We assigned economic values available in euros: $-0.40 €$ for DMI (as feed costs represent around the $40 \%$ of production cost) and $1.00 €$ for ECM, and 0 for MBW. Finally, we had 4 scenarios within each index: (1) only having an economic value for ECM (DMI or RFI economic values were set to zero), referred to as base scenario, (2) including DMI or RFI with an economic value of $-0.40 €$ and including $\mathrm{CH}_{4}$ with an economic value of zero, which represents including $\mathrm{CH}_{4}$ in the breeding goal without penalization; (3) including DMI or RFI with an economic value of $-0.40 €$ and $\mathrm{CH}_{4}$ with an economic value of $-0.30 €$, (4) including DMI or RFI with an economic value of $-0.40 €$ and $\mathrm{CH}_{4}$ with an economic value of $-0.60 €$. Genetic variances, correlations, and heritabilities obtained from this study were used as inputs in the calculation of the correlated responses.

\section{RESULTS AND DISCUSSION}

\section{Descriptive Statistics}

Descriptive statistics for all traits (MeP, GSMet, MeY, MeI, RMet1, RMet2, RMet3, DMI, RFI1, RFI2, $\mathrm{BW}, \mathrm{MBW}, \triangle \mathrm{BW}, \mathrm{BCS}, \mathrm{MY}$, and ECM) for the combined data set are shown in Table 2. Means of MeP, DMI, MY, and BW were $392.3 \mathrm{~g} / \mathrm{d}, 21.3 \mathrm{~kg} / \mathrm{d}, 31.9$ $\mathrm{kg} / \mathrm{d}$, and $624.6 \mathrm{~kg}$, respectively. Descriptive statistics for MeP per country, parity number, stage of lactation, and month are presented in Table 3. Means of MeP in Australia and Switzerland were larger than those in Canada and Denmark. The coefficient of variation of MeP ranged between 17 and $24 \%$ among countries. Means per method of measurement varied between
340.1 (Sniffer 1: Guardian) to $466.1\left(\mathrm{SF}_{6}\right)$, the latter having the lowest coefficient of variation $(17 \%)$. The MeP means per parity ranged between $363.2 \mathrm{~g} / \mathrm{d}$ (first parity) and $398.1 \mathrm{~g} / \mathrm{d}$ (third parity), with a 21 to $26 \%$ coefficient of variation. Finally, means and SD of MeP in mid-lactation were larger than in early and late lactation, but the coefficients of variation were similar among the 3 stages and ranged from 21 to $24 \%$.

\section{Genetic Parameters for All Traits}

Estimated variances, heritabilities and $\mathrm{c}^{2}$ (permanent environmental ratios) for all traits are shown in Table 4. The estimated heritability (SE) for $\mathrm{MeP}$ was 0.21 (0.04), whereas heritabilities for the MeY and MeI were 0.30 and 0.38 , respectively. These heritabilities were similar to previously reported estimates by ManzanillaPech et al. (2016) of 0.23 for MeP, 0.30 for MeY, and 0.42 for MeI. On the contrary, van Engelen et al. (2015) reported lower heritabilities for predicted $\mathrm{CH}_{4}$ traits based on milk mid-infrared spectra $(\mathrm{MeP}=0.17, \mathrm{MeY}$ $=0.21$, and $\mathrm{MeI}=0.18)$. Additionally, Difford et al. (2020) reported 0.26 for $\mathrm{CH}_{4}$ concentration (in ppm) in Danish Holstein, whereas Breider et al. (2018) reported 0.33 for $\mathrm{MeP}$ using $\mathrm{SF}_{6}$ in Australian Holstein. Heritabilities for residual $\mathrm{CH}_{4}$ traits were the lowest, ranging between 0.13 and 0.16 , which were lower to residual $\mathrm{CH}_{4}$ heritabilities (0.18-0.21) previously reported by Richardson et al. (2021) using different definitions of residual $\mathrm{CH}_{4}$ (adjusted phenotypically and genetically for DMI, ECM and FeedSaved) in Australian Holstein cows (as a subset of this data). Furthermore, heritability for GSMet was lower (0.15) than the heritability for $\mathrm{MeP}$, meaning that in standardizing the data, the pro- 
Table 3. Descriptive statistics for methane production in $\mathrm{g} / \mathrm{d}(\mathrm{MeP})$ per country, parity, stage of lactation, and month of lactation

\begin{tabular}{|c|c|c|c|c|c|c|c|}
\hline MeP per ${ }^{1}$ & Number of cows & Number of records & Mean & $\mathrm{SD}$ & Minimum & Maximum & $\mathrm{CV} \%$ \\
\hline AUS & 461 & 2,100 & 466.1 & 80.0 & 226.0 & 650.0 & 17 \\
\hline CAN & 246 & 2,104 & 381.2 & 92.4 & 118.5 & 632.0 & 24 \\
\hline DNK & 2,224 & 10,569 & 345.6 & 69.7 & 101.3 & 626.1 & 20 \\
\hline \multicolumn{8}{|l|}{ Method $^{2}$} \\
\hline $\mathrm{SF}_{6}$ & 461 & 2,100 & 466.1 & 80.0 & 226.0 & 650.0 & 17 \\
\hline \multicolumn{8}{|l|}{ Parity } \\
\hline 1 & 1,235 & 6,210 & 363.2 & 96.1 & 101.3 & 637.0 & 26 \\
\hline 2 & 1,088 & 5,072 & 390.1 & 83.2 & 111.3 & 650.0 & 21 \\
\hline $3+$ & 1,021 & 4,038 & 398.1 & 86.5 & 107.2 & 643.0 & 22 \\
\hline \multicolumn{8}{|l|}{ Stage } \\
\hline Early & 1,548 & 4,780 & 366.1 & 87.7 & 101.3 & 635.0 & 24 \\
\hline
\end{tabular}

${ }^{1}$ AUS $=$ Australia; CAN = Canada; CHE = Switzerland; DNK = Denmark. Early = 0-100 DIM; Mid- = 101-200 DIM; Late = +201 DIM.

${ }^{2} \mathrm{SF}_{6}=$ sulfur hexafluoride tracer gas technique. GreenFeed (C-lock Inc.); Guardian (Edinburgh Instruments Ltd.); Gasmet (Gasmet Technologies $\mathrm{Oy})$.

portion of variation that is explained by additive genetics was reduced and conversely, the relative variation due to permanent environmental factors was enlarged.

The heritability of DMI was 0.24 and in agreement with values reported by Berry et al. (2014) for Canada (0.19) and Australia (0.24) in an international evaluation for feed intake. Although RFI1 and RFI2 had low heritability estimates (0.06 and 0.07 , respectively), they were in the range of the estimates (0.01 to 0.16 ) reported by Berry and Crowley (2013) for RFI in lactating Holstein from several studies. However, Li et al. (2017) and Tempelman et al. (2015) reported heritabilities from 0.10 and 0.29 for RFI in Danish Holstein and in a multicountry study, respectively. Furthermore, estimated heritabilities for maintenance traits varied depending on the trait analyzed, being 0.81 for BW and MBW, 0.31 for BCS, and 0.14 for $\triangle \mathrm{BW}$. Estimated heritabilities for BW and MBW were high with

Table 4. Estimated genetic $\left(\sigma_{a}^{2}\right)$, permanent environmental $\left(\sigma_{p e}^{2}\right)$, and residual $\left(\sigma_{e}^{2}\right)$ variances, heritabilities $\left(\mathrm{h}^{2}\right)$, and permanent environmental ratios $\left(\mathrm{c}^{2}\right)$ with (SE) for methane, production, maintenance, and efficiency traits

\begin{tabular}{lrrrrc}
\hline Trait $^{1}$ & \multicolumn{1}{c}{$\sigma_{a}^{2}$} & \multicolumn{1}{c}{$\sigma_{p e}^{2}$} & \multicolumn{1}{c}{$\sigma_{e}^{2}$} & $\mathrm{~h}^{2}$ & $\mathrm{c}^{2}$ \\
\hline MeP & 725.9 & $1,581.1$ & $1,137.0$ & $0.21(0.04)$ & $0.46(0.04)$ \\
GSMet & 568.6 & $1,955.6$ & $1,358.1$ & $0.15(0.03)$ & $0.50(0.03)$ \\
MeY & 3.3 & 4.8 & 2.9 & $0.30(0.04)$ & $0.44(0.06)$ \\
MeI & 3.7 & 2.9 & 3.2 & $0.38(0.04)$ & $0.29(0.06)$ \\
RMet1 & 358.2 & $1,236.4$ & 875.9 & $0.14(0.03)$ & $0.50(0.04)$ \\
RMet2 & 432.1 & $1,908.0$ & 949.0 & $0.13(0.04)$ & $0.58(0.04)$ \\
RMet3 & 461.2 & $1,692.5$ & 808.9 & $0.16(0.04)$ & $0.57(0.04)$ \\
DMI & 3.7 & 1.7 & 10.3 & $0.24(0.02)$ & $0.11(0.01)$ \\
RFI1 & 0.4 & 1.2 & 5.1 & $0.06(0.02)$ & $0.18(0.01)$ \\
RFI2 & 0.5 & 1.3 & 5.6 & $0.07(0.01)$ & $0.18(0.01)$ \\
BW & $3,44.7$ & 267.4 & 549.0 & $0.79(0.03)$ & $0.06(0.03)$ \\
MBW & 78.2 & 5.7 & 12.2 & $0.79(0.03)$ & $0.06(0.03)$ \\
$\Delta$ BW & 0.12 & 0.15 & 0.58 & $0.14(0.01)$ & $0.18(0.01)$ \\
BCS & 246.0 & 223.6 & 325.6 & $0.31(0.03)$ & $0.28(0.03)$ \\
MY & 14.0 & 11.8 & 21.1 & $0.30(0.03)$ & $0.25(0.02)$ \\
ECM & 8.7 & 8.9 & 20.4 & $0.23(0.02)$ & $0.23(0.02)$ \\
\hline
\end{tabular}

${ }^{1} \mathrm{MeP}=$ methane production; GSMet $=$ genetic standardized methane; $\mathrm{MeY}=$ methane yield; $\mathrm{MeI}=$ methane intensity; RMet1 = residual methane on metabolic BW $(\mathrm{MBW})$ and DMI; RMet2 = residual methane on MBW and ECM; RMet3 = residual methane on MBW, DMI, and ECM; RFI1 = residual feed intake (residual of DMI on MBW, ECM, and $\triangle \mathrm{BW}$ ); RFI2 = residual feed intake (residual of DMI on MBW and ECM); $\Delta \mathrm{BW}$ $=$ change in $\mathrm{BW} ; \mathrm{MY}=$ milk yield . 
corresponding low permanent environmental ratios $\left(c^{2}\right)$, meaning that most of the variance is explained by genetics. Similarly, Spurlock et al. (2012) reported high values for BW heritability (0.74). Finally, heritability estimates for MY and ECM were 0.30 and 0.23 , respectively, and in agreement with the extensively reported heritability estimates in Holstein (Berry et al., 2003; Nixon et al., 2009; Liinamo et al., 2012; Interbull, 2018). Permanent environmental ratios were smaller, or similar to heritability estimates for most of the traits, but larger for $\mathrm{CH}_{4}$ traits, meaning that a considerable portion of the variance was explained by the permanent environmental effects instead of the genetic variance in $\mathrm{CH}_{4}$ traits. Differences in measurement protocols of $\mathrm{CH}_{4}$ emissions ( $\mathrm{SF}_{6}$, GreenFeed, and sniffers), feeding systems and diets (i.e., pasture, silage, concentrate, TMR) per country are factors that possibly contribute to the difference in the permanent environmental variances.

\section{Correlations Within Methane Traits}

Phenotypic and genetic correlations between all traits are shown in Table 5. Genetic correlations between $\mathrm{MeP}$ and adjusted $\mathrm{CH}_{4}$ traits ranged between 0.41 and 0.82. In general, the residual $\mathrm{CH}_{4}$ traits (RMet1, RMet2, and RMet3) were more highly correlated with $\mathrm{MeP}$ than the ratio $\mathrm{CH}_{4}$ traits calculated (MeY and $\mathrm{MeI}$ ), implying that residual traits are more similar to $\mathrm{MeP}$, on which they are based. Correlations between different $\mathrm{CH}_{4}$ phenotypes in the literature are scarce or estimated using predicted phenotypes (from milk mid-infrared and fatty acids. For instance, Van Engelen (2018) reported high correlation estimates between $\mathrm{MeP}$ and MeY (0.63), whereas low MeP and MeI were somewhat lower $(0.20)$ and with large standard errors (0.15-0.28). Similarly, Kandel et al. (2017) reported high genetic correlations between $\mathrm{MeI}(0.71)$ and $\mathrm{MeP}$ predicted from mid-infrared milk spectra. Using respiration chambers, Donoghue et al. (2016) reported genetic correlations of 0.50 between $\mathrm{MeP}$ and $\mathrm{MeY}$ in Angus beef cattle. The genetic correlations within the adjusted $\mathrm{CH}_{4}$ traits were in general positive and large (above 0.70), with the exception of MeY with RMet2 (0.35) and MeI with RMet1 and RMet3 (0.51 and 0.63, respectively). Unlike our result of 0.70, van Engelen (2018) reported a negative genetic correlation $(-0.21)$ between MeY and MeI. However, the correlations between these traits should be taken cautiously as they are predicted MeP phenotype based on mid-infrared data not measured $\mathrm{CH}_{4}$ phenotypes.

Residual $\mathrm{CH}_{4}$ traits (Rmet1, Rmet2, and Rmet3) were strongly correlated with each other, genetically (0.82-0.91) and phenotypically (0.89-0.96). This was expected, as the only difference was that RMet3 takes into account the 3 traits at the same time (MBW, DMI, and ECM) instead of 2 at a time (RMet1 and RMet2). Likewise, Richardson et al. (2021) reported strong genetic $(>0.71)$ and phenotypic $(>0.87)$ correlations between 9 definitions of residual $\mathrm{CH}_{4}$ involving DMI, ECM, and FeedSaved (amount of feed saved per year through assumed improvements in lifetime metabolic efficiency and reduced maintenance requirements) values in Australian Holstein cattle. Furthermore, Richardson et al. (2021) reported genetic correlations between 0.52 to 0.97 between the different residual $\mathrm{CH}_{4}$ traits and $\mathrm{MeP}, \mathrm{MeY}$, and MeI. In addition, Donoghue et al. (2016) reported lower to moderate genetic correlations $(0.32-0.63)$ and strong phenotypic correlations (0.60-0.76) between $\mathrm{MeP}$ and 4 residual $\mathrm{CH}_{4}$ traits. The genetic correlation between the GSMet and MeP was 0.99 , showing that they are the same trait. However, the genetic correlations between GSMet and the adjusted $\mathrm{CH}_{4}$ traits were, in general, slightly lower than the genetic correlation between $\mathrm{MeP}$ and the adjusted $\mathrm{CH}_{4}$ traits. As part of the standardizing process across countries, the genetic variance and covariance were reduced in GSMet compared with MeP. Nonetheless, these genetic correlations were not significantly different from each other due to the large standard errors. Despite this, only minimal differences were found between the standardized trait and $\mathrm{MeP}$, indicating genetic standardization may be the optimal approach for accounting for the variation between countries when merging international data.

\section{Correlations Between Methane Traits and Production Traits}

Genetic correlations were positive and moderate between MeP and MY (0.29), and between MeP and ECM (0.45), the first was similar to the correlation reported (0.26) by Breider et al. (2018) in Australian Holstein whereas the latter was similar to the correlation reported (0.43) by Lassen and Løvendahl (2016) in Danish Holstein. Likewise, Difford et al. (2020) reported genetic correlation of 0.35 between $\mathrm{CH}_{4}$ concentration and FPCM in a combined data set with Danish and Dutch Holstein cows. Furthermore, genetic correlations between GSMet and MY (0.41) and ECM (0.59) were higher than with MeP. Given the moderate positive genetic correlation between $\mathrm{MeP}$ and milk traits, it seems important to adjust for ECM, to achieve a $\mathrm{CH}_{4}$ phenotype that is independent of milk production. Genetic correlations between adjusted $\mathrm{CH}_{4}$ traits and production traits ranged from slightly positive $(0.15$ between MeY and ECM) to moderate and negative $(-0.57$ between MeI and MY). Similar results were 


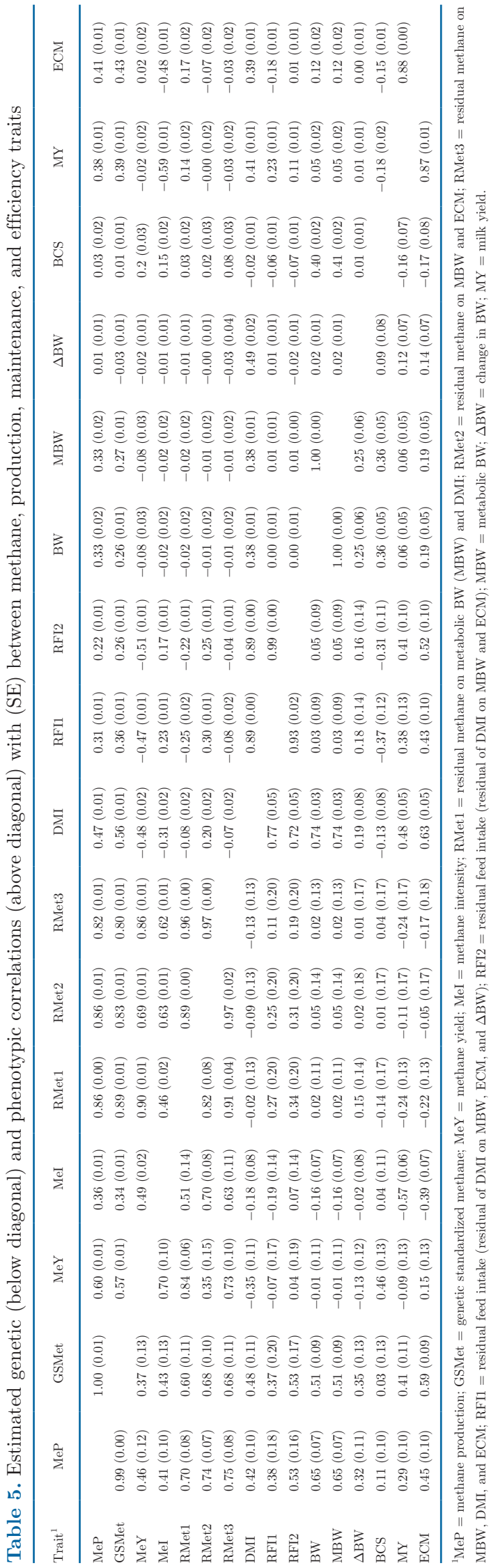

reported by van Engelen (2018) between MeY and MY (-0.39). Recently, Richardson et al. (2021) presented an even stronger negative genetic correlation $(-0.73)$ between ECM and MeI in Australian Holstein cows. Despite MeI being a trait that is simple to explain to farmers, $\mathrm{CH}_{4}$ produced per unit of milk, the strong negative correlation between MeI and ECM means it is not advisable to select for this trait. However, ratio traits present some statistical disadvantages, such as strong correlations with the denominator trait (ECM and DMI, in our case) and difficulty of interpretation of the selection response due to antagonism between the response in the numerator and the denominator (Veerkamp and Emmans, 1995; Berry and Crowley, 2013). Therefore, using MeI as the candidate $\mathrm{CH}_{4}$ trait in the selection index is problematic, as there is likely to be a conflict in selecting for lower emitting animals, as cows producing less milk would be unacceptable to farmers. On the other hand, $\mathrm{MeY}$ has a low negative genetic correlation with MY (-0.09) and low positive genetic correlation with ECM (0.15); however, due to the large standard error, this correlation could be closer to zero, which differs from the value 0.66 reported by van Engelen (2018) and the strong negative correlations $(-0.53$ and -0.68$)$ reported by Richardson et al. (2021) and Kandel et al. (2017), respectively. Furthermore, the estimated genetic correlations between RMet2 and milk traits, as expected, were close to zero, because ECM was one of the regressors for RMet2. The negative genetic correlations between RMet3 (adjusted by MBW, DMI, and ECM) and MY (-0.24) and ECM (-0.17) could imply that adjusting by DMI and ECM double account for some of the overlapping genetic variation due to DMI and ECM, as milk is directly determined by DMI and the RMet2 was corrected phenotypically not genetically. This may be prevented by precorrecting DMI by MY as suggested by Breider et al. (2018). Alternatively, genetic residual $\mathrm{CH}_{4}$ may be calculated instead, but a 4-trait model (MeP, MBW, DMI, and ECM) would be needed to estimate the genetic correlations between the traits. Most of the adjusted $\mathrm{CH}_{4}$ traits, except for MeI and RMet1, had phenotypic correlations close to zero with milk production traits.

\section{Correlations Between Methane Traits and Maintenance Traits}

Only a few studies (Lassen and Løvendahl, 2016; Breider et al., 2018; Difford et al., 2020) have reported genetic correlations between $\mathrm{MeP}$ and $\mathrm{BW}$ in dairy cattle. Furthermore, we have not found studies that reported genetic correlation estimates between $\mathrm{MeP}$ and $\triangle \mathrm{BW}$. Genetic correlations between $\mathrm{MeP}$ and maintenance traits (Table 5) ranged between 0.11 
(BCS) and 0.65 (BW and MBW). Previous reports of genetic correlations between $\mathrm{MeP}$ and $\mathrm{BW}$ in literature varied widely, from negative $(-0.18$; Lassen and Løvendahl, 2016) in TMR-fed Holstein cows, to close to zero for $\mathrm{CH}_{4}$ concentration (0.03; Difford et al., 2020) in Holstein cows; and moderate and positive in grazing heifers (0.42; Breider et al., 2018) to strongly positive (0.80) in growing beef cattle as reported by Donoghue et al. (2016). Furthermore, Zetouni et al. (2018) reported negative correlations between MeP and BCS of -0.28 in a Danish Holstein population (using a subset of the data in the current study). Genetic correlations between GSMet and maintenance traits were weaker (except for $\Delta \mathrm{BW}$ ) than the ones between MeP and maintenance traits. Genetic correlations between adjusted $\mathrm{CH}_{4}$ traits and weight traits (BW, MBW, and $\triangle \mathrm{BW}$ ) varied between -0.16 and 0.15 , whereas phenotypic correlations varied between -0.08 and zero, showing that adjusted $\mathrm{CH}_{4}$ traits are more likely phenotypically independent of weight traits. Finally, genetic correlations between adjusted $\mathrm{CH}_{4}$ traits and BCS were positive (except for RMet1 $=-0.14$ ) and ranged between 0.01 (RMet2) and 0.46 $(\mathrm{MeY})$ with large standard error given the amount of data available. It is recommended, however, to further study the effect of selecting for lower $\mathrm{CH}_{4}$-emitting animals on decreasing body condition, as this could have health and fertility consequences (Tiezzi et al., 2013). Roche et al. (2009) stated in his review that BCS is a nonlinear trait with an optimum range from 3.0 to 3.25 (5-point scale). Lower BCS is associated with reduced production and reproduction, whereas BCS $>3.5$ is associated with reduction in early lactation DMI, MY, and an increased risk of metabolic disorders.

\section{Correlations Between Methane Traits and Efficiency Traits}

Estimating genetic correlations between $\mathrm{CH}_{4}$ and efficiency traits is a key step in linking high feed efficiency to low $\mathrm{CH}_{4}$ emissions in dairy cows. Understanding this relationship is necessary to determine whether selecting for feed efficiency will indirectly result in lower emitting cows. This information will allow us to determine the optimal strategy for including $\mathrm{CH}_{4}$ in future breeding goal, which may consist of constructing a selection index for efficiency by combining both traits. Few studies have reported correlations between MeP and DMI or RFI in dairy and beef cattle, as both traits are scarcely recorded. Genetic correlations between $\mathrm{MeP}$ and feed intake traits ranged between 0.38 (RFI1) and 0.53 (RFI2) with large standard errors (Table 5) due to the scarcity of data in common. Similarly, Difford et al. (2020) reported a genetic correlation (0.33) between genetic RFI and $\mathrm{CH}_{4}$ concentration (ppm) in a bi-country Holstein population. Likewise, positive genetic correlations between MeP and DMI in Australian Holsteins were reported by Breider et al. (2018; 0.34 ) with a subset of Richardson et al. (2021; 0.49). In Australian beef cattle, a higher positive correlation between MeP and DMI (0.83; Donoghue et al., 2016) has been reported compared with our results (0.42). The genetic correlation between GSMet and DMI was slightly higher than that of $\mathrm{MeP}$ with $\mathrm{DMI}$, but remained the same for both residual feed intakes. In all cases, residual $\mathrm{CH}_{4}$ traits were weakly genetically correlated with DMI (ranging from -0.02 to -0.13 ) and phenotypically $(-0.07$ and -0.08 , except Rmet 2$)$. This was expected given that DMI was one of its regressors (RFI1 and RFI3). Methane yield and MeI were negatively genetically correlated with DMI and RFI1, ranging between -0.07 to -0.35 , but not with RFI2 where correlations were weak but positive (0.04 to 0.07 with large $\mathrm{SE}$ ). Residual $\mathrm{CH}_{4}$ traits were positively genetically correlated with residual feed intake traits (from 0.11 to 0.34 ), although with large standard error, meaning that genetically efficient cows could also emit less $\mathrm{CH}_{4}$. Likewise, Richardson et al. (2021) reported positive phenotypic correlations (from 0.26 to 0.47 ) with 5 of the 9 definitions of residual $\mathrm{CH}_{4}$ included in their study and DMI. This is in agreement with several studies (Hegarty et al., 2007; Negussie et al., 2014; Hailemariam et al., 2016) reporting selection for RFI efficient cows would indirectly select for cows that emit less $\mathrm{CH}_{4}$. However, the physiological mechanisms behind this correlation have not been defined and may involve several interacting factors as genetics, environment, diet, and rumen microbiome.

\section{Genetic Parameters for MeP by Country and Method}

In Table 6, the estimated genetic, permanent environmental, and residual variances per country and method are presented. Heritability estimates for MeP were between the ranges of 0.18 to 0.24 for all countries, except for Canada (0.36). However, heritability estimates for Canada, Australia, and Switzerland had large standard errors $(0.11-0.26)$, partially due to the small number of animals with $\mathrm{MeP}$ records available in these countries. Richardson et al. (2021) reported heritability estimates of 0.16 for $\mathrm{MeP}$ for a subset of the Australian data we presented in this study (0.20); however, there is no significant difference (the SE is 0.11 in both studies). Furthermore, the genetic SD varies considerably between countries, being twice as large in Canada (44.7) as in Denmark (22.0), showing a coefficient of genetic variation between 6.3 and $9.6 \%$ among countries. Despite the difference in size of 
genetic variances per country (and its coefficients), all countries showed that $\mathrm{MeP}$ is a heritable trait that can be selected for, and implies the feasibility of combining data from different sources (countries and methods of measurement). However, the lack of data across different methods and countries (method is fully confounded within some countries) does not allow us to determine if there is an interaction between country and method. Moreover, the lack of genetic linkage in terms of common ancestors and sires (with daughters with MeP records), and the lack of genotypes for all the cows with MeP records, restricted us from estimating genetic correlations between countries and determining if $\mathrm{MeP}$ is the same trait across countries, research stations, or methods. Larger amounts of data per country and better-linked pedigree or genomic relationships between countries could be helpful to supply some useful genetic links between the populations and estimate accurate genetic parameters. Additionally, permanent environmental ratios varied widely from 0.26 (Switzerland) to 0.73 (Australia). Differences in measurement protocols of $\mathrm{CH}_{4}$ emissions ( $\mathrm{SF}_{6}$, GreenFeed, and sniffers) and feeding systems and diets (i.e., pasture, silage, concentrate, TMR) per country are factors that possibly contributed to the difference in the permanent environmental variance components. For example, Harper et al. (1999) stated that grass-fed cattle produce up to 4 times more $\mathrm{CH}_{4}$ than grain-fed cattle.

For some countries, like Australia, all cows were measured with a single method $\left(\mathrm{SF}_{6}\right)$ that was not used in other countries. This introduces challenges as the MeP per method using data from multiple countries can provide us with information to unravel the confounding effects of country and method when determining the genetic component related to method and vice versa. The GreenFeed method was used in both Canada and Switzerland, whereas Denmark had the same method, but different sensors (Guardian and Gasmet) analyzed separately as different methods. Heritability estimates ranged between 0.12 (Guardian) and 0.31 (GreenFeed). Greenfeed and Gasmet were the methods with lowest permanent environmental ratio (0.26 and 0.39 , respectively) compared with $\mathrm{SF}_{6}$ and Guardian that had ratios above 0.5. Garnsworthy et al. (2019) summarized previous studies that compared different methods phenotypically reporting Pearson correlations and concordance correlation coefficients (CCC; with large SE) for 7 of the $\mathrm{CH}_{4}$ measurement methods most commonly used. The correlations and CCC for the methods used in this study were as follows: GreenFeed-SF ${ }_{6}$ have a correlation of 0.40 and $\mathrm{CCC}$ of 0.34 , Guardian-GreenFeed have a correlation of 0.64 and CCC of 0.14, and GuardianGasmet have a correlation of 0.97 and CCC of 0.79 . However, all the studies reported by Garnsworthy et al. (2019) had small data sets (from 11 to 48 animals with repetitions) and most of them were pairwise comparisons between methods (not the same animals through all the methods).

At present, different countries use different methods to measure $\mathrm{CH}_{4}$, partially because they have invested in the research and equipment over several years, building a large data collection to estimate accurate $\mathrm{CH}_{4}$ genetic parameters and breeding values. Most importantly, the method with a scope of applications best suited for the conditions in each country was chosen, for instance $\mathrm{SF}_{6}$ for grazing systems in Australia or sniffers in the AMS in Denmark. Therefore, there is not a unique "best" method to measure $\mathrm{CH}_{4}$, but several, depending on the type of production system (full grazing, tiestall, freestall) and environmental conditions. The challenge at this point is to investigate how to combine the data already existing across countries and methods to best inform future practice. This study is one of the first attempts to this approach, providing some insights regarding the feasibility to merge data from different countries, methods, and timelines.

Table 6. Estimated genetic $\left(\sigma_{a}^{2}\right)$, permanent environmental $\left(\sigma_{p e}^{2}\right)$, residual variances $\left(\sigma_{e}^{2}\right)$, heritabilities $\left(\mathrm{h}^{2}\right)$, and permanent environmental ratios $\left(\mathrm{c}^{2}\right)$ with $(\mathrm{SE})$ for methane production $(\mathrm{MeP})$ per country

\begin{tabular}{|c|c|c|c|c|c|}
\hline Trait $^{1}$ & $\sigma_{a}^{2}$ & $\sigma_{p e}^{2}$ & $\sigma_{e}^{2}$ & $h^{2}$ & $c^{2}$ \\
\hline MeP AUS & $1,004.9$ & $3,673.7$ & 292.3 & $0.20(0.11)$ & $0.73(0.11)$ \\
\hline $\mathrm{MeP}$ CAN & $1,998.2$ & $2,227.2$ & $1,315.2$ & $0.36(0.19)$ & $0.40(0.18)$ \\
\hline $\mathrm{MeP}$ CHE & 920.1 & $1,014.8$ & 1901.4 & $0.24(0.26)$ & $0.26(0.26)$ \\
\hline MeP DNK & 482.0 & 795.0 & $1,437.9$ & $0.18(0.05)$ & $0.29(0.04)$ \\
\hline $\mathrm{MeP} \mathrm{SF}_{6}$ & $1,025.8$ & $3,578.0$ & 292.3 & $0.20(0.11)$ & $0.73(0.11)$ \\
\hline MeP GreenFeed & $1,572.9$ & $2,023.8$ & $1,532.1$ & $0.31(0.15)$ & $0.39(0.15)$ \\
\hline MeP Guardian & 451.3 & $2,155.8$ & $1,248.7$ & $0.12(0.05)$ & $0.56(0.05)$ \\
\hline MeP Gasmet & 479.2 & 717.7 & $1,510.1$ & $0.18(0.05)$ & $0.26(0.05)$ \\
\hline
\end{tabular}

${ }^{1} \mathrm{AUS}=$ Australia; $\mathrm{CAN}=$ Canada; $\mathrm{CHE}=$ Switzerland; $\mathrm{DNK}=$ Denmark; $\mathrm{SF}_{6}=$ sulfur hexafluoride tracer gas technique. GreenFeed (C-lock Inc.); Guardian (Edinburgh Instruments Ltd.); Gasmet (Gasmet Technologies Oy). 


\section{Genetic Parameters for MeP Per Parity and Stage of Lactation}

Estimated genetic, permanent environmental, residual variances, and genetic correlations for $\mathrm{MeP}$ in first, second, and third parity, as well as in early, mid-, and late lactation are presented in Table 7. Heritabilities were larger (0.28) in first parity compared with second $(0.25)$ and third parity (0.19). The genetic correlation between first and second parity was the highest (0.91), meaning that first 2 parities are closely related compared with further parities. Genetic correlations deviating from one between parities are common in several traits, including milk and milk components (between 0.50 and 0.90 for different DIM), as reported by Strabel and Misztal (1999). However, the low-moderate genetic correlation (0.48) between first and third parity (third and further) should be taken cautiously given the large standard error (0.21). Furthermore, the genetic correlation between second and further parities was high (0.85) but with large standard error (0.22) as well.

Until the realization of this work, only a couple of studies have investigated genetic variation of $\mathrm{MeP}$ within lactation. Pszczola et al. (2017) reported daily heritabilities from 0.23 to 0.30 within lactation ( 5 to 305 DIM), showing that $\mathrm{MeP}$ has moderate genetic variation within lactation. In addition, Kandel et al. (2017) reported that daily heritabilities (from 5 to 305 DIM) for mid-infrared predicted MeP ranged from 0.20 to 0.27 for first lactation and from 0.16 to 0.26 for second lactation. In our study and Pszczola et al. (2017), larger heritabilities were estimated in the mid- stage of lactation (0.29 and 0.30, respectively) compared with early and late stages $(0.16-0.17$ and $0.23-0.27$, respectively). However, this trend was only the case during first lactation according to Kandel et al. (2017), whereas in second lactation, predicted MeP heritabil- ity decreased from early lactation toward the end of lactation. Furthermore, Pszczola et al. (2017) reported genetic correlations between early and mid- stage of 0.30 , between mid- and late stage of 0.60 , and no correlation (0) between early and late stage of lactation. Conversely, in the present study genetic correlations were highly positive between early and mid- stage (0.98) and mid- and late stage (0.97) and slightly lower between early and late stage of lactation (0.90). Having lower correlations between further DIM has been reported previously in DMI and RFI (Berry et al., 2007; Manzanilla-Pech et al., 2014; Tempelman et al., 2015; Li et al., 2017), meaning that records collected more closely in time are more highly correlated than those with greater periods of time between estimates.

\section{Correlated Responses When Including Methane in the Selection Index}

Given that RMet2 is the closest to being genetically independent of ECM, DMI, and MBW, it appears to be the best-adjusted $\mathrm{CH}_{4}$ trait and a good candidate to be included in the selection index. A similar residual $\mathrm{CH}_{4}$ trait (adjusted only by ECM) was proposed as the candidate trait to be included in the Australian routine genetic evaluations (Richardson et al., 2021) based on its heritability and the practicality of obtaining ECM measurements on a larger number or animals compared with the other traits used as regressors in the calculation of the residual traits. Likewise, due to the high genetic correlation between RFI1 and RFI2 (0.93) and the simplicity of calculation (not including $\Delta \mathrm{BW}$ ), RFI2 was the best candidate selected for this analysis. Correlated response to selection for DMI or RFI (RFI2 only referred as RFI in this section), MBW and ECM using MeP or RMet2 (only referred as RMet in this section) at different economic values: $0,-0.30$, and -0.60

Table 7. Estimated genetic $\left(\sigma_{a}^{2}\right)$, permanent environmental $\left(\sigma_{p e}^{2}\right)$, residual variances $\left(\sigma_{e}^{2}\right)$, heritabilities $\left(\mathrm{h}^{2}\right)$, permanent environmental ratios $\left(\mathrm{c}^{2}\right)$, and genetic correlations $\left(r_{g}\right)$ with (SE) for methane production (MeP) in first, second, and third parity; and early, mid-, and late lactation

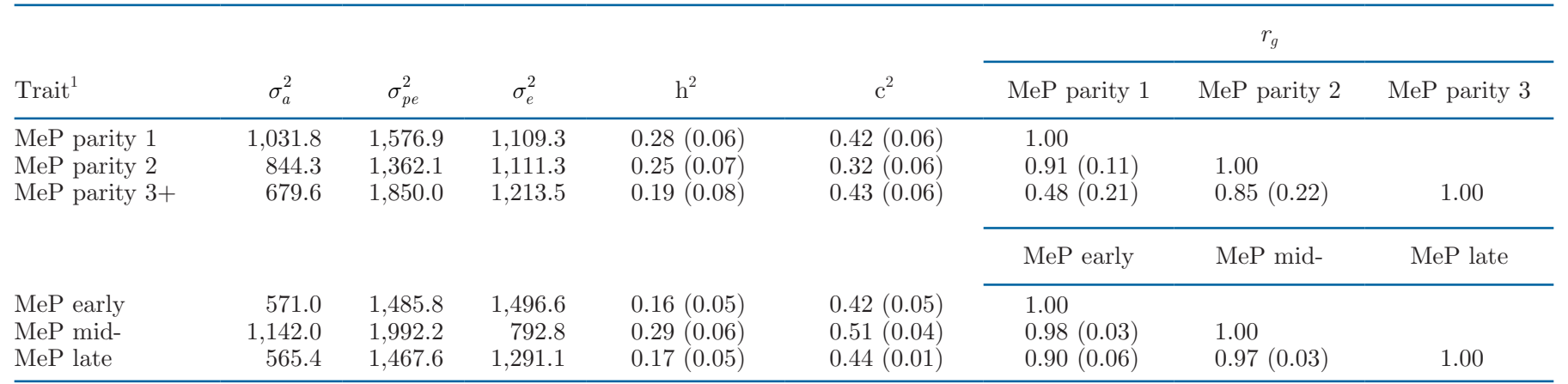

${ }^{1}$ Early $=0-100$ DIM; mid- $=101-200$ DIM; late $=+201$ DIM. 
are presented in Table 8. All base scenarios resulted in similar responses to selection for MBW (indirectly; $\left.1.54 \mathrm{~kg}^{0.75}\right)$ and ECM $(2.64 \mathrm{~kg})$; this represents the top of gain for those 2 traits when selecting only for ECM.

Index 1. By including DMI in the breeding goal, a reduction of $35 \%$ of DMI was achieved together with a $17 \%$ reduction in MeP. If a negative economic value is added to $\mathrm{MeP}$, the reduction may increase to $58 \%$ for $\mathrm{MeP}$ and $46 \%$ for DMI. However, there is also a reduction on $\mathrm{MBW}$, meaning that the reduction on $\mathrm{MeP}$ could be due to the reduction on weight (and body condition) of the cows and this could have a negative effect in milk production in the long term. Roche et al. (2009) stated that cows that calve thinner than between 3.0 and 3.25 (5-point scale) produce less milk, likely have extended postpartum anestrus interval, are less likely to get pregnant, and are more likely to be culled. Likewise, Breider et al. (2018) reported similar trends in the correlated response of $0.69(\mathrm{MeP}),-1.31$ $(\mathrm{MY}),-3.26(\mathrm{BW})$, and -1.19 (DMI) when selecting for reduced DMI, and $-0.47(\mathrm{MY}),-1.96(\mathrm{BW})$ -0.28 (DMI), and -2.94 (MeP) when selecting for reduced MeP. However, negative correlated response could be partially solved by using a restricted selection index where genetic change for particular traits (MBW) are set to 0. Furthermore, there is a reduction in the potential gain for ECM in the more restrictive scenario $(-0.60$ economic value for $\mathrm{MeP})$ of $13 \%$. The main problem of including $\mathrm{MeP}$ in the breeding goal is that it is challenging to disentangle whether the reduction in $\mathrm{MeP}$ is caused indirectly by a reduction in the weight and feed consumption of the animal with a consequently reduction in MY-ECM, or directly by an actual decrease on the $\mathrm{CH}_{4}$ emissions independent of all other traits. However, Gonzalez-Recio et al. (2020) reported a favorable response when incorporating $\mathrm{MeP}$ in the breeding objective, with minor reductions in the expected genetic gain for fat, protein yield, and total economic merit with total $\mathrm{CH}_{4}$ emissions in the dairy industry in Spain.

Index 2. By including RMet instead of $\mathrm{MeP}$, the source of the $\mathrm{CH}_{4}$ reduction is clearly due to a decrease in the MeP independent of BW, DMI, and MY-ECM. A reduction of up to $100 \mathrm{~g} / \mathrm{d}$ can be achieved compared with the base scenario. Likewise, in index 1, this reduction in RMet could be due to a reduction in the weight

Table 8. Correlated response to selection for DMI, residual feed intake (RFI), metabolic BW (MBW), and ECM using methane production $(\mathrm{MeP})$ or residual methane (RMet) at different economic values: $0,-0.30$, and $-0.60^{1}$

\begin{tabular}{|c|c|c|c|c|}
\hline Item & Expected response & Correlated response & Correlated response & Correlated response \\
\hline $\begin{array}{l}\text { Economic value } \\
\text { for } \mathrm{MeP}\end{array}$ & $\begin{array}{c}\text { Expected response } \\
\text { for } \mathrm{MeP}\end{array}$ & $\begin{array}{c}\text { Correlated response } \\
\text { for DMI }\end{array}$ & Correlated response & Correlated response \\
\hline 0 & 0.30 & 0.71 & -0.06 & 2.45 \\
\hline-0.30 & 0.23 & 0.66 & -0.61 & 2.36 \\
\hline-0.60 & 0.15 & 0.59 & -1.18 & 2.31 \\
\hline Base scenario & 0.00 & 1.10 & 1.54 & 2.64 \\
\hline 0 & -0.02 & 0.71 & -0.06 & 2.46 \\
\hline-0.30 & -0.06 & 0.72 & -0.09 & 2.45 \\
\hline-0.60 & -0.10 & 0.73 & -0.12 & 2.44 \\
\hline \multicolumn{5}{|l|}{ Index 3} \\
\hline $\begin{array}{l}\text { Economic value } \\
\text { for } \mathrm{MeP}\end{array}$ & Expected response & Correlated response & Correlated response & Correlated response \\
\hline \multicolumn{5}{|l|}{ Index 4} \\
\hline Economic value & Expected response & Correlated response & Correlated response & Correlated response \\
\hline for RMet & for RMet & for RFI & for MBW & for ECM \\
\hline Base scenario & 0.00 & 0.33 & 1.54 & 2.64 \\
\hline 0 & -0.05 & 0.28 & 1.55 & 2.60 \\
\hline-0.30 & -0.09 & 0.26 & 1.51 & 2.59 \\
\hline-0.60 & -0.13 & 0.24 & 1.46 & 2.55 \\
\hline
\end{tabular}

${ }^{1}$ Base scenario = only including economic value for ECM (1.00€) and zero for DMI, RFI, and MBW. All the other scenarios included economic value for DMI or RFI (-0.40€). All the responses are in kilograms per generation. (Index 1) MeP, DMI, MBW, and ECM; (index 2) RMet, DMI, MBW, and ECM; (index 3) MeP, RFI, MBW, and ECM; and (index 4) RMet, RFI, MBW, and ECM. 
of the animal as the correlated response with MBW is negative. Moreover, the maximum reduction for DMI is $34 \%$ considering the most restrictive scenario $(-0.60)$. Additionally, ECM had a reduction in the total gain of $7.6 \%$ compared with the base scenario, which is substantially lower than in index 1 of $12.5 \%$.

Index 3. When including RFI instead of DMI, a reduction of $15 \%$ in $\mathrm{RFI}$ and $8 \%$ in $\mathrm{MeP}$ compared with the base scenario was achieved. For the more restricted scenario, the reduction in $\mathrm{MeP}$ was $47 \%$ and $33 \%$ for RFI. Moreover, despite the reduction in the potential gain for MBW (62\%) this response was not negative, implying that there may not be a reduction in the weight of the animal. Furthermore, the reduction on the potential gain for ECM $(6 \%)$ is lower compared with index 1 and index 2 . In this index, the problem of reducing $\mathrm{CH}_{4}$ by only reducing the size of the animals was addressed. However, it remains unclear if reducing $\mathrm{MeP}$ is really selecting for lower emitting animals or if it is only a consequence of selecting for more (feed) efficient animals.

Index 4. This scenario had the largest reduction in $\mathrm{CH}_{4}$ (RMet), up to $130 \mathrm{~g} / \mathrm{d}$ in the most restrictive scenario $(-0.60)$. Consequently, there is a reduction of RFI from 15 to $27 \%$ in the different scenarios. Additionally, the reduction in gain for MBW and ECM was the lowest across indexes at 5 and $3 \%$, respectively (representing $95 \%$ and $97 \%$ of the total gain compared with base scenario). Thus, if the aim is to increase milk production while reducing $\mathrm{CH}_{4}$ emissions and feed intake, index 4 gives the best results ranging between +2.55 to $+2.60 \mathrm{~kg}$ of ECM, while reducing RMet in up to $130 \mathrm{~g} / \mathrm{d}$. However, special attention is needed to ensure no increase in MBW while selecting for lower $\mathrm{CH}_{4}$ emitting animals, feed-efficient animals, or both.

In summary, including RFI with a negative economic value in the breeding goal reduces the expected response of $\mathrm{MeP}$ compared with the base scenario, meaning that selecting for more feed-efficient animals is also selecting for lower $\mathrm{CH}_{4}$-emitting animals. This is in agreement with Hegarty et al. (2007) who concluded that breeding for feed-efficient cows (RFI) would reduce $\mathrm{CH}_{4}$ emissions. However, Løvendahl et al. (2018) highlighted some additional issues in their review, as selecting low emitting animals may result in reduced efficiency of plant cell wall degradation and have unknown effects on the rumen microbiome, which plays a role in digestion and MeP. Furthermore, care must be taken when including $\mathrm{MeP}$ in the breeding goal, that reductions are not achieved by breeding for smaller and low-milkproducing cows. Likewise, Lopez-Paredes et al. (2018) concluded that a carbon quota scenario (that included $\mathrm{CH}_{4}$ ) would select smaller cows and consequently lower
$\mathrm{CH}_{4}$ emissions in a study that measured expected consequences of including $\mathrm{CH}_{4}$ footprint into the breeding goal of beef cattle. Additionally, it is important to mention that in the indexes 1 and 2 the reduction of $\mathrm{MeP}$ is only a reduction in the expected gain, given that the values are positive, and it is only by including RMet that a real reduction (negative values) is achieved. Finally, accurate genetic correlations between MeP (and RMet) and health and fertility traits are still needed to measure the correlated response of those traits (that are in many cases already included in the breeding goal) when including MeP.

\section{Implications and Current Situation}

Previous projects (global Dry Matter Initiative) have shown the benefits and limitations of merging international data, and this is especially true for scarce-recorded traits such as feed intake data. Earlier studies set the precedent of gathering a large amount of records and genotypes that otherwise would not be possible (Banos et al., 2012), performing genome association studies (de Haas et al., 2012; Berry et al., 2012), genomic prediction studies, and finally merged genetic evaluations (Berry et al., 2014). These studies have also exposed some of the issues when merging data across countries, such as different production systems, managing and recording differences, and genotype by environmental interactions (Banos et al., 2012; Berry et al., 2014). Nonetheless, there are many advantages, such as increasing the power of detection of QTL and increasing the accuracy in the genomic prediction, while decreasing the bias. The outcome of this research has contributed greatly to the development of breeding values for farmers to breed for improved efficiency, such as Savedfeed in the Nordic countries, FeedSaved in Australia (Pryce et al., 2015), and Feed Saved in the United States (Tempelman et al., 2015).

More recent projects, such as the EDGP, have continued this work by developing databases to store data across countries for several scarce-recorded traits such as feed efficiency and $\mathrm{CH}_{4}$.

This study provides insights on the trait definition for $\mathrm{CH}_{4}$ across countries and some related traits, and the feasibility on merging data across countries. Based on our results we are positive about the possibility of inclusion of $\mathrm{CH}_{4}$ in the breeding goal, either directly or indirectly by some correlated traits (as feed efficiency, RFI). Relatively few studies have tested the inclusion of $\mathrm{CH}_{4}$ in the breeding goal. An exception is GonzalezRecio et al. (2020) who showed that including $\mathrm{CH}_{4}$ in the breeding goal could reduce total $\mathrm{CH}_{4}$ emissions and $\mathrm{CH}_{4}$ intensity in the Spanish dairy industry in the next 
10 yr while maintaining a positive genetic trend for MY.

\section{Future Research}

The confounding of methods and different populations of cows across countries is a limitation. Most methods have only been compared with respiration chambers (as it is the gold standard), but due to practical constraints (costly, measuring only one animal at a time, and being in an artificial environment), currently no country is using this method to collect large amounts of data for genetic purposes. One possible solution is to include a single method across all countries, for example using GreenFeed devices, or the highly portable laser $\mathrm{CH}_{4}$ detector. On the other hand, Negussie et al. (2017) has suggested the use of "proxies" to predict $\mathrm{CH}_{4}$, stating that a single proxy is not enough to predict accurate $\mathrm{CH}_{4}$ emissions, but the combination of 2 or more can increase the accuracy of prediction up to $35 \%$. Among those proxies are milk mid-infrared, rumen metabolites, and microbiome information. As Negussie et al. (2017) implied, proxies could help to disentangle the $\mathrm{CH}_{4}$ differences due to microbiome and diet composition, among others. One of our main results was that including RFI in the breeding goal could help to reduce $\mathrm{CH}_{4}$, due to the moderate positive correlation between RFI and RMet. However, to elucidate the physiological mechanisms (paths) controlling feed efficiency and $\mathrm{CH}_{4}$-efficient cows (cows emitting less $\mathrm{CH}_{4}$ than predicted), it is necessary to do interdisciplinary research involving nutritionists, physiologists, and geneticists. This leads to 2 future avenues of research that could not be addressed with the current database. First, multitrait analyses treating $\mathrm{CH}_{4}$ in different countries or methods as a different trait as well as other potential proxies are needed to better elucidate the genetic potential of these methods under different conditions and countries. Second, it is well known that $\mathrm{CH}_{4}$ emissions are highly influenced by the dietary composition of the feed, and in such a case the potential effect of genotype by environment interaction cannot be ignored. Future studies need to investigate and quantify the potential effect of dietary genotype by environment interaction on the relationship between $\mathrm{CH}_{4}$ emissions and feed efficiency. Finally, a major issue when merging data is the connectedness of the pedigrees; the pedigrees require considerable depth to detect common ancestors, and this could also be avoided by increasing the number of genotypes animals with $\mathrm{CH}_{4}$ records in each country, which would be beneficial in the future to build a genomic reference population. Routine genotyping on the farms could guarantee genomic data in the future.

\section{CONCLUSIONS}

Methane is highly correlated with other economically important traits such as milk production, weight, and feed intake. For this reason, it is important to have a trait that is adjusted for the production traits. Residual $\mathrm{CH}_{4}$ adjusted by MBW and ECM seems to be the best option, given that the genetic correlations are close to zero with its regressors and DMI. Residual $\mathrm{CH}_{4}$ is also positively correlated with RFI, implying that lower $\mathrm{CH}_{4}$-emitting animals are also more efficiently converting feed. Methane varies slightly within lactation, as the genetic correlations at different stages of lactation showed. However, across parities there is larger variation, especially between parity 1 and $3+$. Methane (g/d) has similar heritability estimates across countries and methods, despite the differences in the size of variances. Genetic standardized $\mathrm{CH}_{4}$ presented lower heritability estimates than (unstandardized) $\mathrm{MeP}$, but similar genetic correlations with the other economically important traits. Including RFI in the breeding goal could help to reduce $\mathrm{CH}_{4}$, as the moderate positive correlation between RFI and RMet may result in an indirect, correlated response to selection. Including a negative economic value for $\mathrm{CH}_{4}$ could help to reduce $\mathrm{CH}_{4}$ substantially while maintaining an increase in milk production (95 to $97 \%$ total gain, index 4). Adding RMet in the breeding goal would represent a real reduction in $\mathrm{CH}_{4}$, in comparison to adding $\mathrm{MeP}$ where only the rate of increase is reduced.

\section{ACKNOWLEDGMENTS}

Qualitas (Switzerland), University of Guelph (Canada), Agricultural Victoria (Australia), and Aarhus University (Denmark) as part of the Efficient Dairy Genome Project (EDGP) provided databases. The authors thank the animal nutrition group at ETH Zurich and AgroVet-Strickhof (M. Kreuzer, A. Schwarm, and T. Denninger) and Agroscope Posieux (F. Dohme-Meier, A. Münger) for generously providing their research data. The authors thank Dagnachew Hailemariam for managing and providing data recorded at the University of Alberta's Dairy Research and Technology Center. The authors also acknowledge the funding organizations of the Efficient Dairy Genome Project (i.e. Genome Canada; Ottawa, Canada), Genome Alberta (Calgary, Canada), Ontario Genomics (Toronto, Canada), Alberta Ministry of Agriculture (Edmonton, Canada), Ontario Ministry of Research and Innovation (Toronto, Canada), Ontario Ministry of Agriculture, Food and Rural Affairs (Guelph, Canada), Canadian Dairy Network (Guelph), GrowSafe Systems 
(Airdrie, Canada), Alberta Milk (Edmonton, Canada), Agriculture Victoria Research (Melbourne Australia), Dairy Australia (Melbourne Australia), Gardiner Dairy Foundation (Melbourne, Australia), and University of Melbourne, (Melbourne Australia), Scotland's Rural College (Edinburgh, UK), USDA Agricultural Research Service (Washington, DC), Qualitas AG (Zug, Switzerland), and Aarhus University (Denmark). This work was partially funded by a grant from the Danish Agricultural Agency, an agency under the Ministry of Environment and Food of Denmark (REFFICO, Green Development and Demonstration Program, GUDP, Denmark) and a grant from the Danish Milk Levy Fund (Aarhus, Denmark) for the project "Reduceret klimaaftryk på KO-niveau og BEDRIFTS-niveau." Per Madsen (Aarhus University) is kindly acknowledged for his help regarding the realization of this study. The authors have not stated any conflicts of interest.

\section{REFERENCES}

Amon, B., V. Kryvoruchko, T. Amon, and S. Zechmeister-Boltenstern. 2006. Methane, nitrous oxide and ammonia emissions during storage and after application of dairy cattle slurry and influence of slurry treatment. Agric. Ecosyst. Environ. 112:153-162. https:// doi.org/10.1016/j.agee.2005.08.030.

Banos, G., M. P. Coffey, R. F. Veerkamp, D. P. Berry, and E. Wall. 2012. Merging and characterising phenotypic data on conventional and rare traits from dairy cattle experimental resources in three countries. Animal 6:1040-1048. https://doi.org/10.1017/ S1751731111002655.

Berry, D. P., J. W. M. Bastiaansen, R. F. Veerkamp, S. Wijga, E. Wall, B. Berglund, and M. P. L. Calus. 2012. Genome-wide associations for fertility traits in Holstein-Friesian dairy cows using data from experimental research herds in four European countries. Animal 6:1206-1215. https://doi.org/10.1017/S1751731112000067.

Berry, D. P., F. Buckley, P. Dillon, R. D. Evans, M. Rath, and R. F. Veerkamp. 2003. Genetic parameters for body condition score, body weight, milk yield, and fertility estimated using random regression models. J. Dairy Sci. 86:3704-3717. https://doi.org/10 .3168/jds.S0022-0302(03)73976-9.

Berry, D. P., M. P. Coffey, J. E. Pryce, Y. De Haas, P. Lovendahl, N. Krattenmacher, J. J. Crowley, Z. Wang, D. Spurlock, K. Weigel, K. Macdonald, and R. F. Veerkamp. 2014. International genetic evaluations for feed intake in dairy cattle through the collation of data from multiple sources. J. Dairy Sci. 97:3894-3905. https://doi .org $/ 10.3168 /$ jds. 2013-7548.

Berry, D. P., and J. J. Crowley. 2013. Cell Biology Symposium: Genetics of feed efficiency in dairy and beef cattle. J. Anim. Sci. 91:1594-1613. https://doi.org/10.2527/jas.2012-5862.

Berry, D. P., B. Horan, M. O'Donovan, F. Buckley, E. Kennedy, M. McEvoy, and P. Dillon. 2007. Genetics of grass dry matter intake, energy balance, and digestibility in grazing Irish dairy cows. J. Dairy Sci. 90:4835-4845. https://doi.org/10.3168/jds.2007-0116.

Boadi, D., C. Benchaar, J. Chiquette, and D. Massé. 2004. Mitigation strategies to reduce enteric methane emissions from dairy cows: Update review. Can. J. Anim. Sci. 84:319-335. https://doi.org/10 .4141/A03-109.

Breider, I. S., E. Wall, P. C. Garnsworthy, and J. E. Pryce. 2018. Genetic relationships between methane emission and milk yield, live weight and dry matter intake. Proceedings of the World Congress on Genetics Applied to Livestock Production, Volume Challenges - Environmental, 134, 2018. WCGALP New Zealand.
Dairy Australia. 2018. Body condition scoring. Accessed May 1, 2019 https://www.dairyaustralia.com.au/farm/animal-management/ fertility/body-condition-scoring.

de Haas, Y., M. P. L. Calus, R. F. Veerkamp, E. Wall, M. P. Coffey, H. D. Daetwyler, B. J. Hayes, and J. E. Pryce. 2012. Improved accuracy of genomic prediction for dry matter intake of dairy cattle from combined European and Australian data sets. J. Dairy Sci. 95:6103-6112. https://doi.org/10.3168/jds.2011-5280.

de Haas, Y., M. Pszczola, H. Soyeurt, E. Wall, and J. Lassen. 2017. Invited review: Phenotypes to genetically reduce greenhouse gas emissions in dairying. J. Dairy Sci. 100:855-870. https://doi.org/ $10.3168 /$ jds.2016-11246.

Deighton, M. H., S. R. O. Williams, M. C. Hannah, R. J. Eckard, T. M. Boland, W. J. Wales, and P. J. Moate. 2014. A modified sulphur hexafluoride tracer technique enables accurate determination of enteric methane emissions from ruminants. Anim. Feed Sci. Technol. 197:47-63. https://doi.org/10.1016/j.anifeedsci.2014 .08.003.

Difford, G. F., J. Lassen, and P. Løvendahl. 2016. Interchangeability between methane measurements in dairy cows assessed by comparing precision and agreement of two non-invasive infrared methods. Comput. Electron. Agric. 124:220-226. https://doi.org/10.1016/j .compag.2016.04.010.

Difford, G. F., P. Løvendahl, R. F. Veerkamp, H. Bovenhuis, M. H. P. W. Visker, J. Lassen, and Y. de Haas. 2020. Can greenhouse gases in breath be used to genetically improve feed efficiency of dairy cows? J. Dairy Sci. 103:2442-2459. https://doi.org/10.3168/ jds.2019-16966.

Difford, G. F., D. W. Olijhoek, A. L. F. Hellwing, P. Lund, M. A. Bjerring, Y. de Haas, J. Lassen, and P. Løvendahl. 2019. Ranking cows' methane emissions under commercial conditions with sniffers versus respiration chambers. Acta Agric. Scand. A Anim. Sci. 68:25-32. https://doi.org/10.1080/09064702.2019.1572784.

Difford, G. F., D. R. Plichta, P. Løvendahl, J. Lassen, S. J. Noel, O. Højberg, A. D. G. Wright, Z. Zhu, L. Kristensen, H. B. Nielsen, B. Guldbrandtsen, and G. Sahana. 2018. Host genetics and the rumen microbiome jointly associate with methane emissions in dairy cows. PLoS Genet. 14:e1007580. https://doi.org/10.1371/journal .pgen.1007580.

Donoghue, K. A., T. Bird-Gardiner, P. F. Arthur, R. M. Herd, and R. F. Hegarty. 2016. Genetic and phenotypic variance and covariance components for methane emission and postweaning traits in Angus cattle. J. Anim. Sci. 94:1438-1445. https://doi.org/10.2527/ jas.2015-0065.

FAO, IFAD, UNICEF, WFP, and WHO. 2018. The State of Food Security and Nutrition in the World 2018. Building climate resilience for food security and nutrition. FAO. Accessed Jun. 26, 2019. https: //docs.wfp.org/api/documents/WFP-0000074343/download/?_ga $=2.96598495 .1797860750 .1561542120-8599111.1561542120$.

Garnsworthy, P. C., J. Craigon, J. H. Hernandez-Medrano, and N. Saunders. 2012a. On-farm methane measurements during milking correlate with total methane production by individual dairy cows. J. Dairy Sci. 95:3166-3180. https://doi.org/10.3168/jds.2011-4605.

Garnsworthy, P. C., J. Craigon, J. H. Hernandez-Medrano, and N. Saunders. 2012b. Variation among individual dairy cows in methane measurements made on farm during milking. J. Dairy Sci. 95:3181-3189. https://doi.org/10.3168/jds.2011-4606.

Garnsworthy, P. C., G. F. Difford, M. J. Bell, A. R. Bayat, P. Huhtanen, B. Kuhla, J. Lassen, N. Peiren, M. Pszczola, D. Sorg, M. H. P. W. Visker, and T. Yan. 2019. Comparison of methods to measure methane for use in genetic evaluation of dairy cattle. Animals (Basel) 9:837. https://doi.org/10.3390/ani9100837.

Gonzalez-Recio, O., J. López-Paredes, L. Ouatahar, N. Charfeddine, E. Ugarte, R. Alenda, and J. A. Jiménez-Montero. 2020. Mitigation of greenhouse gases in dairy cattle via genetic selection: 2 . Incorporating methane emissions into the breeding goal. J. Dairy Sci. 103:7210-7221. https://doi.org/10.3168/jds.2019-17598.

Grainger, C., T. Clarke, S. M. McGinn, M. J. Auldist, K. A. Beauchemin, M. C. Hannah, G. C. Waghorn, H. Clark, and R. J. Eckard. 2007. Methane emission from dairy cows measured using the sulfur 
hexafluoride (SF6) tracer and chamber techniques. J. Dairy Sci. 90:2755-2766. https://doi.org/10.3168/jds.2006-697.

Hailemariam, D., G. Manafiazar, J. Basarab, F. Miglior, G. Plastow, and Z. Wang. 2016. Greenhouse gas emission related traits differ in RFI divergent lactating dairy cows. J. Anim. Sci. 94(suppl_5):191. https://doi.org/10.2527/jam2016-0394.

Harper, L. A., O. T. Denmead, J. R. Freney, and F. M. Byers. 1999. Direct measurements of methane emissions from grazing and feedlot cattle. J. Anim. Sci. 77:1392-1401. https://doi.org/10.2527/ 1999.7761392x.

Hegarty, R. S., J. P. Goopy, R. M. Herd, and B. McCorkell. 2007. Cattle selected for lower residual feed intake have reduced daily methane production. J. Anim. Sci. 85:1479-1486. https://doi.org/ $10.2527 /$ jas.2006-236.

Huhtanen, P., E. H. Cabezas-Garcia, S. Utsumi, and S. Zimmerman. 2015. Comparison of methods to determine methane emissions from dairy cows in farm conditions. J. Dairy Sci. 98:3394-3409. https://doi.org/10.3168/jds.2014-9118.

Interbull. 2018. National genetic evaluation forms provided by countries. Accessed Apr. 2, 2019. http://www.interbull.org/ib/geforms.

Johnson, K., M. Huyler, H. Westberg, B. Lamb, and P. Zimmerman. 1994. Measurement of methane emissions from ruminant livestock using a sulfur hexafluoride tracer technique. Environ. Sci. Technol. 28:359-362. https://doi.org/10.1021/es00051a025.

Johnson, K. A., and D. E. Johnson. 1995. Methane emissions from cattle. J. Anim. Sci. 73:2483-2492. https://doi.org/10.2527/1995 $.7382483 x$.

Kandel, P. B., M.-L. Vanrobays, A. Vanlierde, F. Dehareng, E. Froidmont, N. Gengler, and H. Soyeurt. 2017. Genetic parameters of mid-infrared methane predictions and their relationships with milk production traits in Holstein cattle. J. Dairy Sci. 100:5578-5591. https://doi.org/10.3168/jds.2016-11954.

Knapp, J. R., G. L. Laur, P. A. Vadas, W. P. Weiss, and J. M. Tricarico. 2014. Invited review: Enteric methane in dairy cattle production: Quantifying the opportunities and impact of reducing emissions. J. Dairy Sci. 97:3231-3261. https://doi.org/10.3168/jds .2013-7234.

Kristensen, T. 1986. Method for estimation of body condition of dairy cows. Page 17 in Report No. 615. National Institute of Animal Science, Denmark. [in Danish with English subtitles].

Lassen, J., and P. Løvendahl. 2016. Heritability estimates for enteric methane emissions from Holstein cattle measured using noninvasive methods. J. Dairy Sci. 99:1959-1967. https://doi.org/10 $.3168 /$ jds.2015-10012.

Lassen, J., P. Løvendahl, and J. Madsen. 2012. Accuracy of noninvasive breath methane measurements using Fourier transform infrared methods on individual cows. J. Dairy Sci. 95:890-898. https:/ /doi.org/10.3168/jds.2011-4544.

Li, B., B. Berglund, W. F. Fikse, J. Lassen, M. H. Lidauer, P. Mäntysaari, and P. Løvendahl. 2017. Neglect of lactation stage leads to naïve assessment of residual feed intake in dairy cattle. J. Dairy Sci. 100:9076-9084. https://doi.org/10.3168/jds.2017-12775.

Liinamo, A. E., P. Mantysaari, and E. A. Mantysaari. 2012. Short communication: Genetic parameters for feed intake, production, and extent of negative energy balance in Nordic Red dairy cattle. J. Dairy Sci. 95:6788-6794. https://doi.org/10.3168/jds.2012-5342.

Lopez-Paredes, J., R. Alenda, and O. Gonzalez-Recio. 2018. Expected consequences of including methane footprint into the breeding goals in beef cattle. A Spanish Blonde d'Aquitaine population as a case of study. J. Anim. Breed Genet. 135:366-377. https://doi .org/10.1111/jbg.12350.

Løvendahl, P., G. F. Difford, B. Li, M. G. G. Chagunda, P. Huhtanen, M. H. Lidauer, J. Lassen, and P. Lund. 2018. Review: Selecting for improved feed efficiency and reduced methane emissions in dairy cattle. Animal 12:336-349. https://doi.org/10.1017/ S1751731118002276.

Lowman, B. G., N. Scott, and S. Sommervill. 1976. Condition Scoring of Cattle. Bulletin No. 6. The East of Scotland College of Agriculture.

Madsen, J., B. S. Bjerg, T. Hvelplund, M. R. Weisbjerg, and P. Lund. 2010. Methane and carbon dioxide ratio in excreted air for quan- tification of the methane production from ruminants. Livest. Sci. 129:223-227. https://doi.org/10.1016/j.livsci.2010.01.001.

Madsen, P., and J. Jensen. 2014. A user's guide to DMU, version 6 , release 5.0. Cent. Quant. Genet. Genomics Dept. Mol. Biol. Genet. Univ

Manzanilla-Pech, C. I. V., Y. de Haas, B. J. Hayes, R. F. Veerkamp, M. Khansefid, K. A. Donoghue, P. F. Arthur, and J. E. Pryce. 2016. Genome-side association study of methane emissions in Angus beef cattle with validation in dairy cattle. J. Anim. Sci. 94:4151-4166. https://doi.org/10.2527/jas.2016-0431.

Manzanilla-Pech, C. I. V., R. F. Veerkamp, M. P. L. Calus, R. Zom, A. van Knegsel, J. E. Pryce, and Y. De Haas. 2014. Genetic parameters across lactation for feed intake, fat-and protein-corrected milk, and liveweight in first-parity Holstein cattle. J. Dairy Sci. 97:5851-5862. https://doi.org/10.3168/jds.2014-8165.

Mayes, R. W., C. S. Lamb, and P. M. Colgrove. 1986. The use of dosed and herbage n-alkanes as markers for the determination of herbage intake. J. Agric. Sci. 107:161-170. https://doi.org/10.1017/ S0021859600066910.

Negussie, E., Y. de Haas, F. Dehareng, R. J. Dewhurst, J. Dijkstra, N. Gengler, D. P. Morgavi, H. Soyeurt, S. van Gastelen, T. Yan, and F. Biscarini. 2017. Invited review: Large-scale indirect measurements for enteric methane emissions in dairy cattle: A review of proxies and their potential for use in management and breeding decisions. J. Dairy Sci. 100:2433-2453. https://doi.org/10.3168/ jds.2016-12030.

Negussie, E., P. Mantysaari, E. A. Mantysaari, and M. Lidauer. 2014. Animal wise variation in enteric output traits and its relationship with feed efficiency in dairy cattle: A longitudinal model analysis. Pages 2-4 in Proc. 10th World Congr. Genet. Appl. Livest. Prod, Vancouver, Canada.

Nixon, M., J. Bohmanova, J. Jamrozik, L. R. Schaeffer, K. Hand, and F. Miglior. 2009. Genetic parameters of milking frequency and milk production traits in Canadian Holsteins milked by an automated milking system. J. Dairy Sci. 92:3422-3430. https://doi .org/10.3168/jds.2008-1689.

Pryce, J. E., O. Gonzalez-Recio, G. Nieuwhof, W. J. Wales, M. P. Coffey, B. J. Hayes, and M. E. Goddard. 2015. Hot topic: Definition and implementation of a breeding value for feed efficiency in dairy cows. J. Dairy Sci. 98:7340-7350. https://doi.org/10.3168/ jds.2015-9621.

Pszczola, M., K. Rzewuska, S. Mucha, and T. Strabel. 2017. Heritability of methane emissions from dairy cows over a lactation measured on commercial farms. J. Anim. Sci. 95:4813-4819. https: //doi.org/10.2527/jas2017.1842.

Richardson, C. M., T. T. T. Nguyen, M. Abdelsayed, P. J. Moate, S. R. O. Williams, T. C. S. Chud, F. S. Schenkel, M. E. Goddard, I. van den Berg, B. G. Cocks, L. C. Marett, W. J. Wales, and J. E. Pryce. 2021. Genetic parameters for methane emission traits in Australian dairy cows. J. Dairy Sci. 104:539-549. https://doi.org/ $10.3168 /$ jds.2020-18565.

Roche, J. R., N. C. Friggens, J. K. Kay, M. W. Fisher, K. J. Stafford, and D. P. Berry. 2009. Invited review: Body condition score and its association with dairy cow productivity, health and welfare. J. Dairy Sci. 92:5769-5801. https://doi.org/10.3168/jds.2009-2431.

Rodenburg, J. 2004. Factsheet Body Condition Scoring of Dairy Cattle, Order No. 92-122. Dairy Cattle Production Systems Program Lead/OMAFRA. Accessed Mar. 26, 2019. http://www.omafra.gov .on.ca/english/livestock/dairy/facts/00-109.htm.

Seymour, D. J., A. Cánovas, C. F. Baes, T. C. S. Chud, V. R. Osborne, J. P. Cant, L. F. Brito, B. Gredler-Grandl, R. Finocchiaro, R. F. Veerkamp, Y. de Haas, and F. Miglior. 2019. Invited review: Determination of large-scale individual dry matter intake phenotypes in dairy cattle: A systematic review. J. Dairy Sci. 102:7655-7663. https://doi.org/10.3168/jds.2019-16454.

Sjaunja, L. O., L. Baevre, L. Junkkarinen, J. Pedersen, and J. Setala. 1991. A Nordic Proposal for and Energy Corrected Milk (ECM) Formula EAAP Publication 50: Performance Recording of Animals. State of the Art 1990, Centre for Agricultural Publishing and Documentation (PUDOC). 
Strabel, T., and I. Misztal. 1999. Genetic parameters for first and second lactation milk yields of Polish black and white cattle with random regression test-day models. J. Dairy Sci. 82:2805-2810.

Spurlock, D. M., J. C. M. Dekkers, R. Fernando, D. A. Koltes, and A. Wolc. 2012. Genetic parameters for energy balance, feed efficiency, and related traits in Holstein cattle. J. Dairy Sci. 95:5393-5402. https://doi.org/10.3168/jds.2012-5407.

Tempelman, R. J., D. Spurlock, M. P. Coffey, R. F. Veerkamp, L. Armentano, K. Weigel, Y. de Haas, C. Staples, E. E. Connor, Y. Lu, and M. VandeHaar. 2015. Heterogeneity in genetic and non-genetic variation and energy sink relationships for residual feed intake across research stations and countries. J. Dairy Sci. 98:2013-2026. https://doi.org/10.3168/jds.2014.8510.

Tiezzi, F., C. Maltecca, A. Cecchinato, M. Penasa, and G. Bittante. 2013. Thin and fat cows, and the nonlinear genetic relationship between body condition score and fertility. J. Dairy Sci. 96:67306741. https://doi.org/10.3168/jds.2013-6863.

van Engelen, S. 2018. The genetic background of methane emission by dairy cows. PhD thesis. Animal Breeding and Genomics. Wageningen University.

van Engelen, S., H. Bovenhuis, J. Dijkstra, J. A. van Arendonk, and M. H. Visker. 2015. Short communication: Genetic study of methane production predicted from milk fat composition in dairy cows. J. Dairy Sci. 98:8223-8226. https://doi.org/10.3168/jds.2014-8989.

Veerkamp, R. F., and G. C. Emmans. 1995. Sources of genetic variation in energetic efficiency of dairy cows. Livest. Prod. Sci. 44:8797. https://doi.org/10.1016/0301-6226(95)00065-0.

Velazco, J. I., D. G. Mayer, S. Zimmerman, and R. S. Hegarty. 2016. Use of short-term breath measures to estimate daily methane production by cattle. Animal 10:25-33. https://doi.org/10.1017/ S1751731115001603.
Wilmink, J. B. M. 1987. Adjustment of lactation yield for age at calving in relation to level of production. Livest. Prod. Sci. 16:321-334. https://doi.org/10.1016/0301-6226(87)90002-9.

Zetouni, L., M. Kargo, E. Norberg, and J. Lassen. 2018. Genetic correlations between methane production and fertility, health and body type traits in Danish Holstein cows. J. Dairy Sci. 101:2273-2280. https://doi.org/10.3168/jds.2017-13402.

Zimmerman, P., S. Zimmerman, S. Utsumi, and D. Beede. 2011. Development of a user-friendly online system to quantitatively measure metabolic gas fluxes from ruminants. J. Dairy Sci. 94(E-Suppl. 1):760. (Abstr.)

\section{ORCIDS}

C. I. V. Manzanilla-Pech ๑ https://orcid.org/0000-0003-1552-212X

P. Løvendahl ( https://orcid.org/0000-0002-9852-2944

D. Mansan Gordo $\odot$ https://orcid.org/0000-0003-2099-0446

G. F. Difford ๑ https://orcid.org/0000-0002-6792-8722

J. E. Pryce ๑ https://orcid.org/0000-0002-1397-1282

F. Schenkel @ https://orcid.org/0000-0001-8700-0633

S. Wegmann (1) https://orcid.org/0000-0001-8309-9170

F. Miglior (ㄴ) https://orcid.org/0000-0003-2345-8842

T. C. Chud $\odot$ https://orcid.org/0000-0001-7559-1165

P. J. Moate (ㄴ) https://orcid.org/0000-0003-4598-2047

S. R. O. Williams (ㄴ) https://orcid.org/0000-0003-1321-6487

C. M. Richardson (ํ) https://orcid.org/0000-0003-4286-4969

P. Stothard $\odot$ https://orcid.org/0000-0003-4263-969X 